
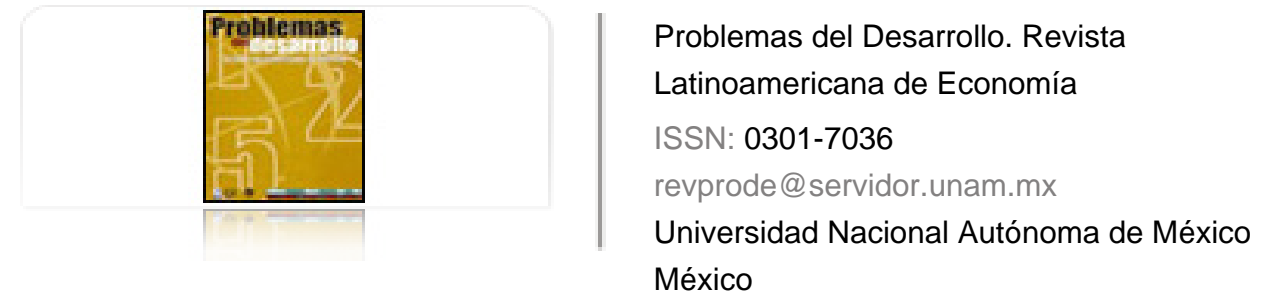

Tovar García, Édgar Demetrio

DESARROLLO INSTITUCIONAL Y DESARROLLO FINANCIERO

Problemas del Desarrollo. Revista Latinoamericana de Economía, vol. 38, núm. 150, julio-septiembre, 2007, pp. 11-41

Universidad Nacional Autónoma de México

Distrito Federal, México

Disponible en: http://www.redalyc.org/articulo.oa?id=11820083002

- Cómo citar el artículo

- Número completo

- Más información del artículo

Página de la revista en redalyc.org

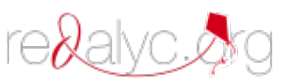

Sistema de Información Científica

Red de Revistas Científicas de América Latina, el Caribe, España y Portugal Proyecto académico sin fines de lucro, desarrollado bajo la iniciativa de acceso abierto 


\section{DESARROLLO INSTITUCIONAL Y DESARROLLO FINANCIERO}

\section{Édgar Demetrio Tovar García *}

Fecha de recepción: 6 de noviembre de 2006. Fecha de aceptación: 17 de abril de 2007.

\section{Resumen}

Profundizar en el entendimiento de los determinantes del desarrollo financiero es una tarea relevante por el nexo positivo que tiene con el proceso de desarrollo económico. Son muchos los factores acusados de favorecer al desarrollo financiero, entre ellos la legislación, la política macroeconómica, la inflación, la cultura, el contexto geográfico, etcétera. En este trabajo se hace un esfuerzo por reunir los determinantes de tipo institucional en una sola línea de explicación, al generar el concepto de desarrollo institucional del sistema financiero y aportar evidencia empírica de sus efectos positivos en el sistema financiero.

Palabras clave: desarrollo financiero, instituciones, desarrollo institucional del sistema financiero y desarrollo económico.

* El autor está becado por la Universidad de Guadalajara, México, a la que le agradece el apoyo recibido. Asimismo, agradece la ayuda brindada por la Universidad de Tampere, Finlandia. Correo electrónico: beno09@yahoo.com

Este trabajo es parte de la tesis doctoral que el autor realiza para obtener el grado de doctor en economía en la Universidad de Barcelona, España. 


\section{Summary}

Deepening the understanding of the determinants of financial development is an important task, given the positive nexus it has with the economic development process. Many prominent factors favor financial development, including legislation, macroeconomic policy, inflation, culture, and the geographical context. This study aims to bring together the institutional determinants in a single line of explanation, generating the concept of institutional development of the financial system and providing empirical evidence of its positive effects on the financial system.

Key words: financial development, institutions, institutional development of the financial system; economic development.

\section{Résumé}

Le développement financier étant lié positivement au processus de développement économique, il est important d'approfondir la compréhension des facteurs qui le déterminent. De nombreux paramètres sont signalés comme favorisant le développement financier, entre autres la législation, la politique macroéconomique, l'inflation, la culture, le contexte géographique, etc. Ce travail s'efforce de réunir les facteurs de type institutionnel en une seule ligne d'explication en introduisant le concept de développement institutionnel du système financier et en apportant la preuve empirique de ses effets positifs sur le système financier.

Mots clés: développement financier, institutions, développement institutionnel du système financier et développement économique.

\section{Resumo}

Aprofundar o entendimento das determinantes do desenvolvimento financeiro é uma tarefa relevante pelo nexo positivo que estas têm com o processo de desenvolvimento econômico. São muitos os fatores acusados de favorecer o desenvolvimento financeiro, entre eles a legislação, a política macroeconômica, a inflação, a cultura, o contexto geográfico, etc. Neste trabalho faz-se um esforço por reunir as determinantes de tipo institucional numa só linha de explicação, ao gerar o conceito de desenvolvimento institucional do sistema financeiro e aportar evidência empirica de seus efeitos positivos no sistema financeiro.

Palabras chave: Desenvolvimento Financeiro, Instituições, Desenvolvimento Institucional do Sistema Financeiro e Desenvolvimento Econômico. 


\section{Introducción}

$\mathcal{L}$

a literatura económica coincide en señalar que existe un nexo positivo entre el desarrollo financiero y el proceso de desarrollo económico. Pero, ¿cuáles son los principales determinantes del desarrollo financiero? Levine (2004) señala que existen dos grandes líneas de análisis: 1) leyes, regulación y política macroeconómica, y 2) política, cultura y geografía. Al analizar estas dos grandes líneas de estudio se encuentra que los elementos explicativos de tipo institucional prevalecen en ambas. Así pues, si bien es cierto que la división de estudio recomendada por Levine es útil para no perderse en la tarea de investigación, también es cierto, tal como señalan Nissanke y Stein (2003), que la trasformación del sistema financiero es primordialmente una transformación institucional.

La intención de este trabajo no es señalar cuál es el factor clave que determina el desarrollo financiero, no es la discusión en la que interesa entrar, sino partir de la postura teórica que dice que el desarrollo institucional favorece el desarrollo financiero. La propuesta es construir una teoría del desarrollo institucional y sus efectos en el desarrollo del sistema financiero, entendiendo que las leyes o reglamentos, por un lado, y la religión y la cultura, por otro lado, son parte del contexto institucional y que ambas deben desarrollarse institucionalmente para promover el desarrollo financiero. En el primer apartado de este trabajo se expone brevemente el papel jugado por los determinantes más citados sobre el desarrollo financiero. Posteriormente, en el segundo, se elabora una síntesis teórica que conjuga los elementos explicativos institucionales del desarrollo financiero. En el tercero se presentan las variables financieras e institucionales a las que se tiene acceso para construir una prueba empírica del nexo entre desarrollo institucional y desarrollo financiero. Una última sección de conclusiones cierra el estudio.

\section{Determinantes del desarrollo financiero}

La eficacia y la eficiencia con la que cada sistema financiero cumple sus funciones marcan su grado de desarrollo financiero. Si seguimos la clasificación de Levine (2004:5), las funciones del sistema financiero son: 1) producir información sobre las posibilidades de inversión y localización del capital, 2) monitorear las inversio- 
nes y ejercer un gobierno adecuado en la empresa (corporate governance) tras recibir el financiamiento, 3) facilitar la administración del riesgo, 4) movilizar y reunir ahorros, y 5) facilitar el intercambio reduciendo los costos de transacción. Si se cumplen cabalmente estas funciones básicas, el resultado será un efecto positivo en el proceso de crecimiento y desarrollo económicos.

El nexo positivo entre el desarrollo financiero y el crecimiento o desarrollo económico ha destacado la necesidad de analizar y entender los determinantes del desarrollo financiero. Levine (2004:86) menciona que existen dos grandes líneas de investigación acerca de esta relación. En primer lugar, hay un grupo creciente de investigación que examina el efecto que las políticas macroeconómicas, las leyes y las regulaciones tienen sobre el funcionamiento del sector financiero. Por su parte, en la segunda agenda de investigación, se estudia lo político, lo cultural, e incluso el contexto geográfico como determinantes del desarrollo financiero.

\section{La política macroeconómica}

como determinante del desarrollo financiero

Se sostiene que las políticas monetarias y fiscales pueden afectar la estructura impositiva de los intermediarios financieros y con ello la provisión de servicios en la materia, lo que repercute negativamente en el desarrollo financiero. Roubini y Sala-i-Martin (1995) señalan que las naciones pueden adoptar una política económica financieramente represiva ${ }^{1}$ con la intención de evitar la usura, controlar la oferta monetaria, localizar el capital en actividades que el gobierno considera prioritarias, suavizar la deuda gubernamental al afectar las tasas de interés a su conveniencia, y porque es una manera fácil de obtener recursos para el presupuesto público. Un gobierno que se encuentre en un marco de evasión fiscal tendrá incentivos a la represión financiera para obtener recursos por medio de la inflación, que funcionaría como un impuesto.

Asimismo, la inflación genera fricciones en el mercado que conllevan a la racionalización del crédito, cada vez más severo conforme la tasa de inflación aumenta. Como resultado, el sector financiero hace pocos préstamos y la colocación

1 Por política de represión financiera se entiende la opción y capacidad de no permitir al sector financiero operar a su máximo potencial por medio de todo tipo de regulaciones, leyes, y otras restricciones ajenas al mercado que afectan la conducta de bancos y otros intermediarios financieros generales. 
de los recursos es menos eficiente, la actividad de los intermediarios financieros disminuye con efectos adversos en las inversiones. El trabajo empírico de Boyd, Levine y Smith (2001) muestra que la inflación tiene un gran impacto no lineal sobre la bolsa de valores y el desarrollo del sistema bancario. En los países de baja inflación los datos indican que más inflación no se empareja con mayores rendimientos nominales de los activos. En cambio, en las economías con alta inflación dichos rendimientos se mueven a la par con los aumentos marginales de la inflación. La actividad prestamista de los bancos, la emisión de obligaciones bancarias, el tamaño de la bolsa de valores y su liquidez están correlacionados negativa y fuertemente con la inflación, pero sólo para los países con tasa de inflación de baja a moderada. Cuando aumenta la inflación, el impacto marginal de la inflación adicional en el sector bancario y en el desarrollo de la bolsa de valores disminuye rápidamente.

\section{La legislación como determinante \\ del desarrollo financiero}

La teoría de la ley y las finanzas (law and finance theory) ${ }^{2}$ sostiene que: 1) siglos atrás, en Europa, se formaron tradiciones legislativas que se extendieron por todo el mundo por medio de la conquista, la colonización y la imitación; 2) cada tradición legislativa difiere en lo que se refiere a la prioridad que se da a la protección de los derechos de propiedad privada de los inversionistas vis-à-vis con el Estado, y 3) los derechos de propiedad privada forman la base de los contratos financieros y del desarrollo financiero global.

Si seguimos a La Porta et al. (1998), la tradición legislativa puede ser británica, francesa, alemana o escandinava, y las diferencias del origen legislativo ayudan a explicar las diferencias en la legislación de los derechos del acreedor, del accionista y de la propiedad privada y ello, a su vez, del desarrollo financiero global. En especial, el derecho consuetudinario británico desde sus inicios fue pensado para proteger a los propietarios, incluso de la corona, de tal forma que podían realizar transacciones con bastante confidencialidad con repercusiones positivas para el desarrollo financiero. En cambio, el derecho civil francés fue construido para eliminar el papel de una magistratura corrupta, solidificar el poder estatal y restringir la interferencia de las cortes con la política estatal.

${ }^{2}$ En esta visión sobresalen los trabajos de La Porta et al. (1997, 1998, 1999 y 2006). 
Con el tiempo, la dominación estatal produjo una tradición legal que se enfoca más en los derechos del Estado y menos en los derechos de inversionistas individuales, a diferencia del derecho consuetudinario británico. Las naciones que han adoptado la tradición legislativa del derecho civil francés tenderán a poner menos énfasis en la protección de la propiedad privada y, en consecuencia, tendrán niveles más bajos de desarrollo financiero que los países con una tradición legislativa basada en el derecho consuetudinario británico. Las legislaciones de origen alemán y escandinavo se encuentran en un punto intermedio entre la británica y la francesa.

Además de que las tradiciones legislativas difieren en la prioridad que dan a los derechos de propiedad privada en relación con los derechos del Estado, también difieren en lo que se refiere a su sensibilidad a cambiar (adaptabilidad) ante las condiciones socioeconómicas. Los sistemas legales más flexibles promueven de mejor manera el desarrollo financiero que los sistemas más rígidos y en este aspecto la tradición francesa es deficiente.

La politica como determinante del desarrollo financiero

Se menciona que el desarrollo financiero puede afectar los intereses de algunos grupos, quienes buscarán inferir en el gobierno y la política para evitar la transformación del sistema financiero, y sostener de esta manera los beneficios que ellos obtienen de un sistema financiero subdesarrollado.

Rajan y Zingales (2003) encuentran que el principal determinante del desarrollo financiero son las fuerzas políticas. Estos autores analizan su crecimiento durante el siglo xx y encuentran que su nivel prevaleciente a principios de siglo sólo se recupera a finales del mismo, por lo que rechazan la idea de que el desarrollo financiero sólo tiende a avanzar y resaltan que existe un retroceso en los años intermedios del siglo xx. Además, indican que la apertura comercial, que en muchos sentidos es resultado de una decisión política, es un determinante del desarrollo financiero, sobre todo cuando va acompañada de flujos internacionales de capital. Esto es así por que la apertura abre camino a la competencia y los "grupos de interés" se ven obligados a favorecer el crecimiento en un intento por encontrar nuevas ventajas económicas abandonadas tras ser incapaces de mantener los privilegios de los años de subdesarrollo financiero. 
Aspectos culturales como determinantes

del desarrollo financiero

Los elementos culturales, es decir, la transmisión de generación en generación de conocimientos, valores y otros factores que influyen el comportamiento, son un determinante importante del desarrollo financiero. Stulz y Williamson (2003) explican que la cultura puede afectar al sistema financiero, al menos, por tres canales. Primero, los valores que son predominantes en un país dependen de su cultura. Por ejemplo, el cobro de intereses pueden ser un pecado en una religión pero no en otra. Segundo, la cultura afecta a las instituciones, es decir, el sistema legal es influenciado por los valores culturales. Tercero, la cultura afecta la forma como se asignan los recursos en una economía. Hay religiones que animan el gasto en iglesias o armas, tomando recursos que podrían dirigirse a inversiones más productivas.

Stulz y Williamson (2003) utilizan la religión como una medida que permite aproximar el nivel cultural y analizan su relación con medidas de protección de los derechos de propiedad privada de los inversionistas. ${ }^{3}$ Encuentran que la cultura (religión) explica en mayor medida la variación de los derechos del acreedor que el origen legislativo; en cuanto al indicador de hacer cumplir la ley, ambos factores tienen un papel importante. En cambio, con la variable que indica el grado de protección de los tenedores de títulos la cultura no presenta ninguna relación. Por otro lado, se encuentra que la cultura está relacionada con el desarrollo bancario y el mercado de deuda, pero no con el mercado de acciones, para el cual el origen legal sigue siendo predominante. En todos los casos, un país protestante está mejor relacionado con estos indicadores. Asimismo, se corroboraron estos resultados incluyendo otras variables explicativas como el ingreso per capita, la apertura comercial y el lenguaje.

Guiso, Sapienza y Zingales (2004) examinan el efecto del capital social en el desarrollo financiero. En dicho estudio el nivel de confianza ${ }^{4}$ en las relaciones económicas, en especial las financieras, tiene el papel más importante en la determinación del crecimiento. Financiar no es más que un intercambio, el acreedor

Utiliza los indicadores elaborados por La Porta et al. (1998).

Guiso, Sapienza, y Zingales (2004) presentan una breve revisión del concepto de capital social, sin llegar a una conclusión tajante, de tal suerte que el nivel de confianza en una sociedad puede ser considerado como la definición de capital social, pero también existen autores que le añaden otros elementos como las normas y las redes que se entretejen en la sociedad para que ésta ejerza su poder, haga cumplir sus leyes y logre sus objetivos. 
entrega una suma de dinero hoy bajo la promesa del prestatario de devolver esa cantidad de dinero más un extra (interés) en el futuro. Para que tal intercambio se lleve acabo no sólo es necesario un contrato y su cumplimiento, sino además un grado de confianza en el funcionamiento del sistema financiero. De hecho, los contratos financieros están diseñados para elevar el grado de confianza. Así pues, el capital social (o nivel de confianza) es relevante en la explicación del desarrollo financiero y las diferencias de éste entre países.

\section{La dotación geográfica como determinante}

del desarrollo financiero

La teoría de la dotación (endowment theory) adapta al sector financiero la llamada hipótesis geográfica y la hipótesis institucional del desarrollo. ${ }^{5}$ Esta última analiza el efecto colonizador de los europeos en el resto del mundo. Señala que los colonizadores europeos adoptaron estrategias distintas en el proceso colonizador, por lo que las instituciones implantadas en una u otra colonia eran disímiles. Por ello, se implantaron instituciones extractivas (malas) en las colonias que hoy son los países subdesarrollados, y que bien podrían haber tenido un nivel de desarrollo elevado en el periodo anterior a la colonización, como México, Perú e India, que antes de la colonia albergaban a sociedades avanzadas como la azteca, la inca y la mughal. Ocurrió lo contrario en colonias que hoy son países ricos, como Estados Unidos, Canadá, Australia y Nueva Zelanda, que antes de la colonia albergaban pueblos con un bajo nivel de desarrollo, y que durante y tras el periodo colonial obtuvieron buenas instituciones. ${ }^{6}$ Por su parte, la hipótesis geográfica señala que el contexto geográfico —el ambiente - afecta directamente al desarrollo económico, pues determina los insumos de la producción y la función de producción en sí misma. El contexto geográfico influye en la calidad de la tierra, el trabajo y la tecnología y los países más cercanos a un clima tropical son los más afectados. ${ }^{7}$

5 Para una revisión de la hipótesis institucional del desarrollo véanse los trabajos de Coatsworth (1998), Sokoloff y Engerman (2000) y Acemoglu et al. (2001, 2002, 2003).

6 En estos estudios también se menciona que no existe una tendencia natural hacia las buenas instituciones. Por el contrario, las élites que padecen las malas instituciones impiden su mejora.

$7 \quad$ Uno de los principales exponentes de esta teoría es Diamond (1999), véase Acemoglu et al. (2002) para una discusión entre las dos hipótesis, la institucional y la geográfica. También véase Easterly y Levine (2003) para un estudio complementario de ambas visiones en la explicación del desarrollo. 
Las hipótesis institucional y geográfica, que en principio buscan explicar sólo el desarrollo económico, son adaptadas por la teoría de la dotación para explicar el desarrollo del sistema financiero, y señalan que el contexto geográfico influyó en la formación de instituciones financieras implantadas por los europeos alrededor del mundo y las cuales han perpetuado su esencia hasta hoy. El trabajo empírico de Beck, Demirgüç-Kunt y Levine (2003a) encuentra que tanto las instituciones implantadas por los europeos como la dotación de factores del contexto geográfico son determinantes importantes del desarrollo del mercado de acciones y del nivel de protección de los derechos de propiedad privada. No obstante, la dotación de factores del contexto geográfico está asociada de manera más robusta que el origen de la legislación con el desarrollo de los intermediarios financieros. Asimismo, la dotación de factores explica en mayor medida la variación del desarrollo financiero. Aunque Easterly y Levine (2003) encuentran que la dotación de factores sólo influye en el desarrollo por medio de las instituciones.

\section{Desarrollo institucional como determinante del desarrollo financiero}

En el apartado previo se han expuesto las principales teorías que explican el desarrollo financiero. Se siguió la división de estudio propuesta por Levine (2004) que permite acercarnos al tópico de una manera ordenada pero carece de una interpretación adecuada de los determinantes institucionales del desarrollo financiero.

Con North (1990) tenemos dos tipos de instituciones; las formales y las informales. ${ }^{8}$ Las instituciones formales son aquellas que están escritas y debidamente establecidas bajo un marco constitucional; son leyes y reglamentos que establecen los márgenes de acción dentro de la legalidad y guían la conducta de los agentes económicos. Las informales, aunque tienen la misma finalidad que las formales, son producto de la tradición y la costumbre, y no están necesariamente escritas dentro del marco constitucional, por lo que pueden coincidir o no con las instituciones formales. Por tanto, desde esta perspectiva institucional, hay motivos para considerar dentro de una misma explicación la teoría de la ley y las finanzas y los determinantes culturales y políticos del desarrollo financiero, ya que la primera esencialmente es una institución formal y los otros encajan en la definición de

8 Con la definición de institución informal North, de alguna manera, rescata la visión de los institucionalistas originales (Veblen, Ayres, Commons y Mitchell). Para una discusión de las semejanzas y diferencias entre las visiones institucionalistas véase Parada (2003). 
institución informal. Así pues, en lugar de que estos factores explicativos del desarrollo financiero sean abordados bajo dos líneas de investigación, sería más indicado generar un solo elemento explicativo del desarrollo financiero; el desarrollo institucional.

\section{Desarrollo institucional del sistema financiero}

La transformación que debe sufrir el sistema financiero para mejorar el cumplimiento de sus funciones y desarrollarse es fundamentalmente una transformación institucional, señalan Arestis, Nissanke y Stein (2005), Arestis y Stein (2005) y Nissanke y Stein (2003). ${ }^{9}$ Para analizar esta transformación institucional estos autores proponen una teoría institucional-céntrica (intitutional-centric theory), donde el sistema financiero es desagregado en cinco componentes institucionales: 1) Las normas, que proporcionan guías de conducta básicas y surgen de la estima social y de la sanción dentro del modelo establecido de banca. 2) Los incentivos, que consisten en las recompensas y las penas que resultan de las diferentes formas de comportarse dentro de sistema financiero. 3) Las regulaciones, que son las fronteras legales para la actuación de los agentes económicos financieros. 4) Las capacidades, que son los conocimientos y habilidades de los agentes económicos financieros para operar eficientemente bajo las normas, las regulaciones y los objetivos de las organizaciones financieras. 5) Las organizaciones, que son entidades financieras legalmente reconocidas que concatenan a grupos de personas con reglas definidas y objetivos comunes.

Nissanke y Stein (2003) elaboran una tabla que contiene cada una de estas cinco categorías institucionales, criterios de evaluación de las mismas y metas institucionales. La tabla tiene un carácter muy genérico. Por ejemplo, en cuanto a la categoría de regulaciones, uno de los criterios de evaluación es el grado de claridad, y la meta institucional es facilitar la accesibilidad y entendimiento de la regulación. Se presupone que las instituciones ya existentes están allí para ayudar a cumplir las funciones del sistema financiero, y que si éstas no se cumplen adecuadamente es porque no se han conseguido las metas institucionales. Los cinco com-

9 Destacan la necesidad de abordar el sistema financiero $-\mathrm{y}$ la globalización financieradesde una perspectiva institucional. Indican que las crisis financieras de los noventa no se pueden achacar a la secuencia de pasos seguidos en el proceso de apertura financiera, sino a una falla teórica: no se previó adecuadamente el marco institucional. 
ponentes institucionales tendrían que ser evaluados y posteriormente orientados hacia las metas institucionales. Si esto se hace de manera correcta, se verá reflejado en el desarrollo financiero y, luego, en el crecimiento y desarrollo económico.

Sin embargo, las instituciones de las distintas economías son muy diversas entre sí. Esto ocurre incluso entre los países europeos que, siendo los más integrados, no tienen exactamente las mismas normas, incentivos, regulaciones, capacidades u organizaciones, aunque algunas de ellas, sobre todo las de carácter internacional, puedan coincidir. En otras palabras, si bien es cierto que en Europa hay un intento por homogeneizar el marco institucional, también es cierto que este proceso sólo ha avanzado hasta un nivel mínimo (Islam, 2004).

Por tanto, el marco institucional de cada país tiene particularidades y, si bien es posible realizar la evaluación y conseguir las metas institucionales conforme a lo planteado por Nissanke y Stein (2003), no debe perderse de vista que ello es válido sólo para cada economía. Ahora bien, en las economías de mercado los diversos marcos institucionales tienen objetivos institucionales comunes: reforzar las instituciones fundamentales del sistema. Es decir, cada nación tiene distintas instituciones en el nivel más desagregado, pero en el nivel más agregado éstas coinciden. Francia e Inglaterra tienen instituciones diferentes en los niveles más desagregados como, por ejemplo, los criterios para constituir empresas, pero coinciden en las instituciones fundamentales de una economía de mercado: 1) la propiedad o apropiación privada y 2) el mercado de libre competencia. A este nivel de generalización es posible aplicar la misma evaluación para cualquier país, ya que el criterio de referencia es el mismo. Esta tarea no sería posible bajo los criterios de Nissanke y Stein (2003), pues en su caso estaríamos evaluando, por ejemplo, la claridad de las leyes, que por su nivel de desagregación pueden ser muy distintas entre países.

A diferencia de Arestis, Nissanke y Stein, en lugar de intentar el análisis y evaluación de la gran diversidad de marcos institucionales (tarea de legisladores), se enfocaría al sistema financiero en relación con sus instituciones económicas fundamentales: la primacía de los derechos de propiedad y la libre competencia en el mercado financiero. Por tanto, el desarrollo institucional del sistema financiero ocurre cuando sus instituciones refuerzan a dichos organismos fundamentales, lo que permite el mejor desempeño de sus funciones básicas. 
Los efectos del desarrollo institucional

en las funciones básicas del sistema financiero

En los mercados donde no prevalece la libre competencia y los derechos de propiedad privada son débiles se generan resultados de asignación de recursos subóptimos; en particular, Claessens y Laeven (2002) encuentran que la adquisición de activos tangibles en relación con los intangibles es mayor en países donde los derechos de propiedad privada no están bien establecidos, pues los inversionistas consideran que la retribución es más fiable en activos tangibles y como resultado no se adquiere la cantidad adecuada de activos intangibles, lo que perjudica el desarrollo financiero.

Los derechos de propiedad privada pueden reforzarse al modificar la legislación y al obligar a los agentes económicos a presentar toda la información requerida por el resto de agentes financieros para la toma de decisiones en la actividad económica. Como resultado del fortalecimiento de los derechos de propiedad privada los agentes económicos acudirán al mercado, lo que incrementará el número de oferentes y demandantes de activos financieros y, por tanto, aumentará el grado de competencia; por la teoría económica sabemos que los precios resultantes dotarán la información necesaria y adecuada para la toma de decisiones y la correspondiente asignación de los recursos. Esta mejora en la información permite que el sistema financiero se desarrolle y cumpla de manera más eficiente con dicha función.

Los derechos de propiedad privada suelen reforzarse al fortalecer y al hacer cumplir los derechos de los accionistas. De esta manera estarán en mejores condiciones para monitorear el uso que se haga de sus recursos. Además, si el mercado accionario es libre y competitivo se genera un monitoreo intrínseco, pues los accionistas podrán vender aquellas acciones donde el uso de los recursos es inadecuado para comprar documentos donde las inversiones se hagan de mejor manera, forzando a que todos busquen un adecuado corporate governance.

Cuando los derechos de propiedad están bien establecidos, los ahorradores no tienen que gastar recursos para asegurarse de recibir lo que les corresponde, y el riesgo de perder los ahorros por razones ajenas a la marcha normal de la economía, como prácticas fraudulentas o expropiación, es mínimo. Si el mercado financiero se vuelve más competido los agentes financieros ofrecerán una mayor variedad de activos financieros al intentar atraer clientes; esa mayor diversidad de activos da opciones para que los agentes financieros adquieran una cartera de activos que les permita diversificar el riesgo. 
Con un marco de fuertes derechos de propiedad privada los ahorradores tendrán confianza para movilizarse y reunirse. Si además el mercado es competido, sabrán que recibirán un precio justo, lo que les motivará a acudir al mercado para prestar sus ahorros.

Debido a que la fortaleza de los derechos de propiedad privada y el desempeño en el mercado de libre competencia proporciona información adecuada, así como un monitoreo eficaz del uso de recursos, reducción y diversificación del riesgo y reunión de ahorros, es de esperar que el contacto de la economía financiera con la real sea menos costosa y que las transacciones en el sector real de la economía sean más eficientes.

\section{Contribución empírica}

No es posible encontrar medidas que capturen adecuadamente lo que se entiende por desarrollo financiero, es decir, no existen medidas que permitan capturar el grado de eficacia y eficiencia con que cada sistema financiero desempeña sus funciones básicas. ${ }^{10}$ Así los trabajos empíricos han optado por utilizar medidas típicas del mercado crediticio y del mercado de acciones, es decir, medidas del crecimiento del sistema financiero, y siempre que éste crece, se supone, también se desarrolla. ${ }^{11}$ En este trabajo se utilizan tres medidas del mercado crediticio: crédito doméstico al sector privado (DCPS), crédito doméstico proporcionado por el sector bancario (DCPBS) y pasivos líquidos o M3 (LLY). Y otras dos medidas referidas al mercado bursátil: acciones comercializadas, valor total (STTV) y acciones comercializadas, en proporción al volumen de ventas (STTR). ${ }^{12}$

Por otra parte, medir el desarrollo institucional del sistema financiero es una tarea compleja, sobre todo por la escasez de bases de datos que contengan variables institucionales. Para medir el nivel de desarrollo de las instituciones se debe tener un punto de referencia que permita la acción de comparar; en este sentido, recuérdese que aquí se considera que el desarrollo institucional dentro de una economía de mercado debe acercarse a las dos instituciones básicas del sistema: el mercado de

10 Esta deficiencia ha sido señalada múltiples veces, en particular véase el trabajo de Levine (2004).

11 Básicamente es el mismo supuesto que se hace con respecto al crecimiento económico y el desarrollo económico, para utilizar el PIB como una medida de este último.

12 La fuente es World Development Indicator 2003. En el apéndice véase el cuadro 12 para la descripción de las variables. 
libre competencia como principal asignador y la protección de los derechos de propiedad (o apropiación) privada. Es importante distinguir las variables que miden las instituciones formales de las informales, pues es posible que si las instituciones informales funcionan adecuadamente no sea necesario construir instituciones formales, así como también es posible que, a pesar de existir las instituciones formales, las informales vayan en dirección opuesta. En concatenación ambos tipos de instituciones producen un resultado que también ha de considerarse. De hecho, Glaeser et al. (2004), al analizar los trabajos que relacionan el desarrollo institucional con el proceso de crecimiento y desarrollo económico, señalan que estos estudios se apoyan en indicadores que miden resultados de las instituciones y no su nivel de desarrollo. Es decir, no miden las leyes, reglas o costumbres que gobiernan una economía, sino que miden resultados económicos que este conjunto de reglas produce, aunque esos resultados bien podrían provenir de distintos contextos institucionales (véase cuadro 1). Los trabajos realizados por La Porta et al. (1998, 1999 y 2006), Glaeser et al. (2004), Kaufmann et al. (2003) y Beck et al. (1999) proporcionan una serie de medidas institucionales que pueden adecuarse al objetivo de este trabajo. Esas variables se presentan en el cuadro 2.

\section{Especificación econométrica}

Tras las notas sobre las variables financieras que se van a utilizar, el siguiente paso es elaborar la prueba empírica que permita verificar el efecto positivo que teóricamente se dijo en el subtema "Los efectos del desarrollo institucional de las funciones básicas del sistema financiero" de este artículo, es decir, del fortalecimiento formal e informal de los derechos de apropiación privada y la competencia financiera, sobre la capacidad del sistema financiero para dotar de la información necesaria a los agentes financieros, monitorear las inversiones, diversificar el riesgo, reunir los ahorros y reducir los costos de la transacción y de la conexión entre el sector real y el financiero, es decir, lo que se conoce como desarrollo financiero y que puede ser medido con indicadores de crecimiento del mercado crediticio y bursátil. Para explorar dicho nexo es factible utilizar el siguiente modelo:

[1] $\Delta D F_{i}=\gamma_{0}-\gamma_{1} D I S F_{1}-\gamma_{2} D F_{1}-\gamma_{3} X_{1}-\gamma_{4}$ Dummies $-u_{i}$ 
Donde, $\triangle \mathrm{DF}$ es la variación en las medidas de desarrollo (crecimiento) financiero enunciadas en la sección previa. En el caso de las medidas de desarrollo del mercado crediticio DCPS, DCPBS y LLY la variación se calcula al restar el promedio de los años 1995-2000 menos el promedio de los años 1980-1985. Asimismo, $\mathrm{DF}_{\mathrm{I}}$ es el valor inicial de estas medidas de desarrollo financiero, calculado como el promedio de los años 1980-1984. En el caso de las variables relacionadas con el mercado bursátil STTV y STTR la variación es calculada con la diferencia del promedio de los años 1998-2000 y 1988-1990 y el valor inicial de la variable es el promedio de los años 1988-1990. ${ }^{13}$ DISF es el desarrollo institucional del sistema financiero, medido con las variables mencionadas en la sección previa, mismas que están clasificadas según se correspondan con los derechos de propiedad privada o con el mercado de libre competencia, así como por su carácter de institución formal, informal o variable de resultado (véase el cuadro 2). $X$ es un conjunto de variables de control; el logaritmo del PIB per capita en términos PPP $^{14}$ (GDPPLN), que es una variable que generalmente funciona bien como variable de control; la tasa de inflación (INFLA), que para muchos estudiosos es un determinante importante del desarrollo financiero; y, según el trabajo de Rajan y Zingales (2003), la apertura comercial (xм), medida como la razón de la suma de importaciones y exportaciones sobre el PIB. ${ }^{15}$ Las dummies son variables del nivel de ingreso, país emergente (D1) y país desarrollado (D2), dejando como grupo base a las naciones subdesarrolladas. ${ }^{16}$

La hipótesis que se va a contrastar es que el desarrollo financiero depende positivamente del nivel de desarrollo institucional del sistema financiero. Es de esperar que haya una relación inversa con el nivel de desarrollo financiero inicial. Y con las variables de control, a excepción de la tasa de inflación, se espera una relación positiva. El tamaño de muestra varía según la medida de desarrollo institucional y desarrollo financiero que se utilice. La muestra base es de 47 países. $^{17}$

13 Tanto la variación como el valor inicial de las medidas de desarrollo financiero se calculan promediando los años especificados para evitar que las fluctuaciones de un solo año afecten un comportamiento que se corresponde con un periodo mayor, a la vez que se corrigen deficiencias estadísticas.

14 Paridad del poder adquisitivo (purchasing parity power).

15 Las cifras de las variables de control son del año 2000 y la fuente es el World Development Indicator 2003.

16 Para la clasificación de subdesarrollados, emergentes y desarrollados véase el cuadro 11 en el apéndice.

17 Véase el cuadro 11 en el apéndice. 
El modelo [1] se corre por MCO y se le incrustan las diferentes combinaciones de medidas de desarrollo financiero e institucional que son posibles con los datos disponibles. Cuando la variable protección del inversionista (PROTEC) se utiliza como medida del desarrollo institucional del sistema financiero — que es indicativa del grado de protección de los derechos de propiedad privada desde la perspectiva de las instituciones formales-, el resultado del modelo es una relación positiva y significativa al nivel de $10 \%$, con una de las tres medidas de desarrollo del mercado crediticio y con el crédito doméstico al sector privado (DCPS). La relación es más fuerte con las variables que miden el desarrollo del mercado bursátil; con ambas existe una relación positiva: a 5\% de significancia con la variable acciones comercializadas, valor total (STTV), y la significatividad con respecto a las acciones comercializadas en proporción al volumen de ventas (STTR) es débil, alcanzando significancia al nivel de $17 \%$ (véase el cuadro 3). Los modelos resultantes de la combinación de la variable explicativa PROTEC y las diferentes medidas de desarrollo financiero no arrojan, en términos generales, r-cuadradas altas, por lo que las variables de control tampoco entran en su mayoría de manera significativa. La única variable de control que presenta un comportamiento significativo con algunas de las medidas de desarrollo financiero es la medida de apertura comercial (xм). Extraña que no haya significancia con las otras variables de control, en especial con la inflación que para algunos estudiosos es un determinante importante del desarrollo financiero. Asimismo, las dummies no son significativas al indicar que el nivel de ingreso de un país no es relevante para los resultados del modelo.

La otra medida de institución formal relacionada con los derechos de propiedad privada - hacer cumplir (HACERC) — sólo tiene una relación débilmente significativa con la variable sTTv, que indica el grado de desarrollo del mercado bursátil. Las variables explicativas (incluyendo las dummies), en general, no presentan coeficientes significativos a excepción de la variable de apertura comercial (хм). Además las r-cuadradas no son altas (véase el cuadro 4).

Por tanto, las medidas de instituciones formales relacionadas con los derechos de propiedad privada presentan para algunos casos una relación positiva y significativa, en particular con las medidas de desarrollo financiero relacionadas con el mercado bursátil.

En cuanto a las variables institucionales de tipo informal correspondientes con la fortaleza de los derechos de propiedad privada, se encuentra que la autoridad de la ley (RLAW) no tiene ninguna relación significativa. En tanto que la variable control de la corrupción (CORRU) presenta una relación significativa, pero negativa a 
10\% de nivel de significancia con la variable M3 o pasivos líquidos (LLY). En cambio, la variable riesgo de expropiación se relaciona positiva y significativamente con las tres medidas de desarrollo financiero relacionadas con el mercado crediticio; DCPS, DCPBS y LLY a 5\%, 5\% y 10\% del nivel de significancia en cada caso. En cuanto al comportamiento del resto de las variables explicativas sólo en algunos casos la medida de apertura comercial (Хм) se relaciona significativamente con la variable dependiente. Las r-cuadradas en general no son altas (véase cuadros 5, 6 y 7).

Por su parte, la medida institucional informal correspondiente al mercado de libre competencia, acceso a acciones (ACCESO), se relaciona positiva y significativamente con las medidas de desarrollo financiero correspondientes al mercado bursátil; STTV y STTR a $1 \%$ y $10 \%$ de significancia respectivamente. Además, tiene un coeficiente positivo y significativo a $11 \%$ con la variable DCPs (véase cuadro 8). En las distintas regresiones la apertura comercial (хм) sigue siendo la única variable de control que presenta un coeficiente significativo con algunas de las variables dependientes. Las r-cuadradas no son altas.

A pesar de que la variable control de la corrupción (CORRU) presenta una relación inversa con una de las medidas de desarrollo financiero (LLY), se puede decir en términos generales que las medidas de desarrollo institucional informal del sistema financiero se relacionan positivamente con el desarrollo financiero.

Por otro lado, la medida institucional de resultado, desconcentración de la propiedad (DESCONPR), correspondiente al mercado de libre competencia, se relaciona significativa y positivamente con dos de las tres medidas de desarrollo del mercado crediticio; DCPS y DCPBS a $5 \%$ y $10 \%$ de significancia respectivamente. Con las medidas de desarrollo del mercado bursátil también existe una relación positiva, aunque la significatividad con respecto a STTR es de $13 \%$ y con STTV de $5 \%$ (véase cuadro 9).

La variable desconcentración bancaria (DESCONB) se relaciona positivamente con las tres medidas de desarrollo del mercado crediticio, aunque la significatividad es baja con DCPS y DCPBS a $17 \%$ y $16 \%$ respectivamente, mientras que con LLY alcanza una significancia al nivel de 1\% (véase cuadro 10). La apertura comercial (xM) continúa siendo la única variable de control que entra significativamente en la mayoría de las regresiones.

En suma, se encuentra que las medidas de desarrollo institucional están relacionadas positiva y significativamente con las medidas de desarrollo financiero, aunque la intensidad de esta relación depende del tipo de variable institucional utilizada y del tipo de medida de desarrollo financiero que se utilice. 


\section{Conclusión}

Son muchos los determinantes del desarrollo financiero que han sido analizados por los estudiosos: origen legislativo, política fiscal y monetaria, inflación, confianza, cultura, religión, grupos de interés, contexto geográfico, etcétera. En este trabajo se ha hecho un esfuerzo por unir todos aquellos determinantes de tipo institucional en una sola variable explicativa. Así se creó el concepto de desarrollo institucional del sistema financiero, es decir, aquel contexto institucional que privilegia los derechos de propiedad privada y al mercado de libre competencia como principal asignador. De tal forma que el desarrollo institucional es un proceso que tiene lugar cuando los cambios institucionales refuerzan a estas dos instituciones de primer orden.

El desarrollo institucional es un elemento clave para que el sistema financiero proporcione de manera más eficiente información financiera, favorezca el monitoreo de las inversiones, facilite la reunión de los ahorros, la diversificación del riesgo y, en general, la relación del sector financiero con el sector real de la economía. Es decir, el desarrollo institucional favorece las funciones básicas del sistema financiero y, por tanto, el crecimiento financiero.

A excepción de las medidas institucionales de tipo formal, el resto, las informales y de resultados, coloca a las naciones más ricas como las más desarrolladas institucionalmente. La prueba empírica aquí elaborada respalda la relación positiva entre el desarrollo institucional y el desarrollo financiero, aunque debe señalarse que, en particular, las medidas institucionales correspondientes al mercado de libre competencia se relacionan de mejor manera. La variable institucional informal acceso a acciones (ACCESO) se relaciona positiva y significativamente con el mercado bursátil. Por su parte, la medida institucional de resultado, desconcentración de la propiedad (DESCONPR), se relaciona significativa y positivamente tanto con el mercado crediticio como con el bursátil. De igual manera, pero sólo con el mercado crediticio, se encuentra una realción positiva y significativa con la variable desconcentración bancaria (DESCONB). Asimismo, las medidas de instituciones formales (PROTEC y HACERC), relacionadas con los derechos de propiedad privada, presentan una relación positiva y significativa particularmente con el mercado bursátil. Y la variable institucional informal riesgo de expropiación (EXPROPIA), también indicativa del grado de protección de los derechos de propiedad privada, se relaciona positiva y significativamente con el mercado crediticio. 
Así, los resultados de esta investigación resaltan la necesidad de prestar más atención a los aspectos institucionales del sistema financiero, y no sólo a los elementos económicos más ortodoxos, si se quiere tener un sistema financiero desarrollado, con la segunda intención de favorecer los procesos de crecimiento y desarrollo económicos.

\section{Bibliografía}

Acemoglu, D. y Johnson, S., "Unbundling Institutions", MA: National Bureau of Economic Research, Documento de Trabajo núm. 9934, Cambridge, 2003.

Acemoglu, D. Johnson, S. y Robinson J. A., "Reversal of Fortune: Geography and Development in the Making of the Modern World Income Distribution", Quarterly Journal of Economics, núm. 117 (4), 2002, pp. 1231-1294.

, "The Colonial Origins of Comparative Development: An Empirical Investigation", American Economic Review, núm. 91 (5), 2001, pp. 1369-1401.

Arestis, P. Nissanke, M. y Stein, H., "Finance and Development: Institutional and Policy Alternatives to Financial Liberalization Theory", Eastern Economic Journal, núm. 31 (2), 2005, pp. 245-63.

Arestis, P. y Stein, H., "An Institutional Perspective to Finance and Development as an Alternative to Financial Liberalization", International Review of Applied Economics on Finance and Development, núm. 19 (4), 2005, pp. 381-98.

Beck, T. Demirgüç-Kunt A. y Levine, R., "Finance, Inequality and Poverty: CrossCountry Evidence", University of Minnesota (Carlson School of Management), mimeo, 2004.

, "Law, Endowments, and Finance", Journal of Financial Economics, núm. 70, 2003a, pp. 137-181.

, "Law and Finance: Why Does Legal Origin Matter?" Journal of Comparative Economics, núm. 3, 2003b, pp. 653-675. -, "A New Database on Financial Development and Structure", Banco Mundial, Documento de Trabajo, núm. 2146, Washington, DC, 1999.
Boyd, J. H. Levine, R. y SmitH, B. D., "The Impact of Inflation on Financial Sector Performance", Journal of Monetary Economics, núm. 47, 2001, pp. 221-248.

Claessens, S. Demirgüç-Kunt, A. y Huizinga H., "How Does Foreign Entry Affect Domestic Banking Markets?", Journal of Banking and Finance, núm. 25, 2001, pp. 891-911.

Coatsworth, J. H., "Economic and Institutional Trajectories in Nineteenth-Century Latin America", en Coatsworth, J. H. y Taylor A. M., (eds.), Latin America and the World Economy since 1800, Massachusetts, Harvard University Press, 1998, pp. 23-54.

Diamond J., Armas gérmenes y acero: la sociedad humana y sus destinos, Madrid, Debate, 1998.

Easterly, W. y Levine, R., "Tropics, Germs, and Crops: How Endowments Influence Economic Development", Journal of Monetary Economics, núm 50, 2003, pp. 3-39.

Glaeser, E. La Porta, R. Lopez-de-Silanes F. y Shleifer, A., "Do institutions cause growth?", MA: National Bureau of Economic Research, Documento de Trabajo, núm. 10568, Cambridge, 2004. Datos en: http:// mba.tuck.dartmouth.edu/pages/faculty/ rafael.laporta/publications.html.

Guiso, L., Sapienza, P. y Zingales, L., "The Role of Social Capital in Financial Development", American Economic Review, núm. 94, 2004, pp. 526-556.

Islam, R., "What Are the Right Institutions in a Globalizing World? And... can we keep them if we've found them?", World Bank Policy Research, Documento de Trabajo núm. 3448, Washington, DC, 2004.

Kaufmann, D. Kraay, A. y Mastruzzi, M., "Governance Matters III:. Governance Indicators for 1996-2002”. World Bank Policy Research, Documento de Trabajo, 
núm. 3106, Washington, DC, 2003. Versión revisada 5 de abril del 2004. Datos en: www.worldbank.org/wbi/governance/ govdata2002/.

La Porta, R. Lopez-de-Silanes, F. y Shleifer, A., "What Works in Securities Laws?", Journal of Finance, núm 61, 2006, pp. 1-32. Datos en: http://post.economics.harvard.edu/ faculty/shleifer/papers/securities_data.xls.

-, "Corporate ownership around the world”, Journal of Finance, núm. 54, 1999 , pp. 471-517.

La Porta, R. Lopez-de-Silanes, F. Shleifer, A. y Vishny, R. W., "Law and Finance", Journal of Political Economy, núm. 106(6), 1998, pp. 1113-1155.

. "Legal Determinants of External Finance", Journal of Finance, núm. 52, 1997, pp. 1131-1150.

Levine, R., "Finance and Growth: Theory and Evidence", MA: National Bureau of Economic Research, Documento de Trabajo, núm. 10766, Cambridge, 2004.

Nissanke, M. y Stein, H., "Financial Globalization and Economic Development:
Toward an Institutional Foundation", Eastern Economic Journal, vol. 29 núm. 2, primavera, 2003, pp. 287-308.

North, D. C., Institutions, Institutional Change and Economic Performance, Nueva York, Cambridge University Press, 1990.

Parada, J., "Economía institucional original y nueva economía institucional: semejanzas y diferencias", Revista de Economía Institucional, vol. 5 núm. 8, Bogota, Universidad Externado, segundo semestre 2003, pp. 92-116.

Rajan, R. G. y Zingales, L., "The great reversals: the politics of financial development in the twentieth century", Journal of Financial Economics, núm. 69, 2003, pp. 5-50

Sokoloff, K. L. y Engerman, S. L., "History Lessons: Institutions, Factor Endowments, and Paths of Development in the New World", Journal of Economic Perspective, núm. 13 (3), 2000, pp. 217-232

Stulz, R. M. y Williamson, R., "Culture, Openness, and Finance", Journal of Financial Economics, núm. 70, 2003, pp. 313-349. 
Anexo

Cuadro 1

Variables institucionales y su clasificación

\begin{tabular}{llll}
\hline $\begin{array}{l}\text { Variable } \\
\text { institucional }\end{array}$ & \multicolumn{1}{c}{ Formal } & \multicolumn{1}{c}{ Informal } & \multicolumn{1}{c}{ Resultado } \\
\hline $\begin{array}{l}\text { Derechos } \\
\text { de propiedad }\end{array}$ & $\begin{array}{l}\text { Conjunto de leyes y re- } \\
\text { glas constitucionales } \\
\text { que protegen y hacen } \\
\text { cumplir los derechos de } \\
\text { propiedad privada. }\end{array}$ & $\begin{array}{l}\text { Conjunto de } \\
\text { costumbres y reglas } \\
\text { culturales que protegen } \\
\text { y hacen cumplir los } \\
\text { derechos de propiedad } \\
\text { privada. }\end{array}$ & $\begin{array}{l}\text { Medidas de apropiación } \\
\text { propiedad. }\end{array}$ \\
$\begin{array}{l}\text { Mercado de libre } \\
\text { competencia }\end{array}$ & $\begin{array}{l}\text { Conjunto de leyes y } \\
\text { reglas constitucionales } \\
\text { que protegen y hacen } \\
\text { cumplir la libre compe- } \\
\text { tencia en el mercado. }\end{array}$ & $\begin{array}{l}\text { Conjunto de costumbres } \\
\text { protegen y hacen } \\
\text { cumplir la libre compe- } \\
\text { tencia en el mercado. }\end{array}$ & $\begin{array}{l}\text { Medidas de concen- } \\
\text { tración del mercado. }\end{array}$ \\
& & & \\
\hline
\end{tabular}

Cuadro 2

Variables institucionales disponibles según su clasificación

\begin{tabular}{lcc}
\hline $\begin{array}{l}\text { Variable } \\
\text { institucional }\end{array}$ & Formal & Informal \\
\hline
\end{tabular}

Derechos Protección del Inversio- Autoridad de la Ley

de propiedad nista (PROTEC) dato (RLAW), dato puntual del

puntual del año $2000 . \quad$ año 2000.

Hacer cumplir (HACERC) Control de la Corrupción

dato puntual del año (CORRU), dato puntual del

$2000 . \quad$ año 2000.

Fuente: La Porta et al. Fuente: Kaufmann et al.

(2006).

(2003).

Riesgo de Expropiación

(EXPROPIA) promedio

1982-1997. Fuente:

Glaeser et al. (2004)

Mercado

de libre

competencia
Acceso a acciones (ACCESO), dato puntual del año 1999.

Fuente: La Porta et al. (2006).
Desconcentración de la propiedad (DESCONPR), dato puntual del año1996. Fuente: La Porta et al. (2006).

Desconcentración bancaria (DESCONB) serie de1990 a 2001). Fuente: Beck et al. (1999). Base de datos actualizada en el año 2003. 
Cuadro 3

Desarrollo del sistema financiero y protección del inversionista

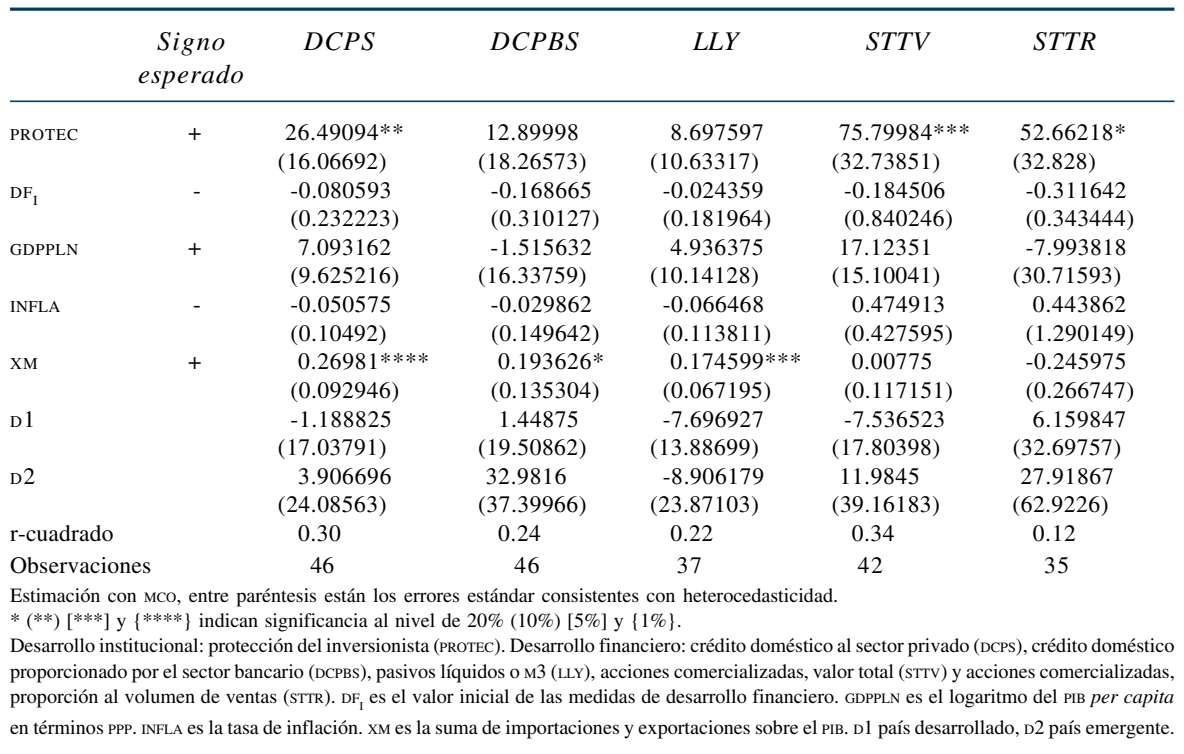

Fuente: Elaboración propia con estimaciones de Econometric Views y datos del Banco Mundial: World Development Indicador 2003 y La Porta et al., 2006

\section{Cuadro 4}

Desarrollo del sistema financiero y hacer cumplir

\begin{tabular}{|c|c|c|c|c|c|c|}
\hline & $\begin{array}{c}\text { Signo } \\
\text { esperado }\end{array}$ & $D C P S$ & $D C P B S$ & $L L Y$ & STTV & STTR \\
\hline HACERC & + & $\begin{array}{c}0.403856 \\
(23.38885)\end{array}$ & $\begin{array}{l}-20.67769 \\
(29.52219)\end{array}$ & $\begin{array}{r}1.409302 \\
(16.96127)\end{array}$ & $\begin{array}{c}54.69204 * \\
(43.37991)\end{array}$ & $\begin{array}{c}13.76365 \\
(52.93596)\end{array}$ \\
\hline $\mathrm{DF}_{\mathrm{I}}$ & - & $\begin{array}{l}-0.084819 \\
(0.231294)\end{array}$ & $\begin{array}{l}-0.206596 \\
(0.279517)\end{array}$ & $\begin{array}{l}-0.037001 \\
(0.176047)\end{array}$ & $\begin{array}{c}0.059994 \\
(0.794766)\end{array}$ & $\begin{array}{l}-0.434849 * \\
(0.307694)\end{array}$ \\
\hline GDPPLN & + & $\begin{array}{r}8.439299 \\
(10.05449)\end{array}$ & $\begin{array}{c}-0.123034 \\
(16.83003)\end{array}$ & $\begin{array}{r}5.560683 \\
(10.22473)\end{array}$ & $\begin{array}{c}20.3543^{*} \\
(15.87004)\end{array}$ & $\begin{array}{c}1.342828 \\
(30.62538)\end{array}$ \\
\hline INFLA & - & $\begin{array}{l}-0.119477 \\
(0.094351)\end{array}$ & $\begin{array}{l}-0.088875 \\
(0.131314)\end{array}$ & $\begin{array}{l}-0.091719 \\
(0.107698)\end{array}$ & $\begin{array}{c}0.377693 \\
(0.352452)\end{array}$ & $\begin{array}{c}0.309738 \\
(1.338356)\end{array}$ \\
\hline хм & + & $\begin{array}{l}0.256744 * * * \\
(0.105897)\end{array}$ & $\begin{array}{c}0.182671 \\
(0.149329)\end{array}$ & $\begin{array}{l}0.175303 * * * \\
(0.065418)\end{array}$ & $\begin{array}{l}-0.030931 \\
(0.138585)\end{array}$ & $\begin{array}{l}-0.255213 \\
(0.287279)\end{array}$ \\
\hline D1 & & $\begin{array}{c}-4.305618 \\
(17.19881)\end{array}$ & $\begin{array}{c}-0.434943 \\
(21.06494)\end{array}$ & $\begin{array}{c}-8.996547 \\
(14.43332)\end{array}$ & $\begin{array}{l}-16.78639 \\
(20.36695)\end{array}$ & $\begin{array}{c}-9.282332 \\
(37.05133)\end{array}$ \\
\hline D2 & & $\begin{array}{l}-0.142876 \\
(23.92366)\end{array}$ & $\begin{array}{l}28.09418 \\
(36.8864)\end{array}$ & $\begin{array}{l}-9.997619 \\
(24.15838)\end{array}$ & $\begin{array}{c}4.037435 \\
(39.77949)\end{array}$ & $\begin{array}{l}7.380597 \\
(71.7232)\end{array}$ \\
\hline r-cuadrado & & 0.26 & 0.25 & 0.22 & 0.27 & 0.10 \\
\hline Observaciones & & 46 & 46 & 37 & 42 & 35 \\
\hline \multicolumn{7}{|c|}{$\begin{array}{l}\text { Desarrollo institucional: hacer cumplir (HACERC). Desarrollo financiero: crédito doméstico al sector privado (DCPS), crédito doméstico proporcionado } \\
\text { por el sector bancario (DCPBS), pasivos líquidos o M3 (LLY), acciones comercializadas, valor total (STTV) y acciones comercializadas, proporción } \\
\text { al volumen de ventas (STTR). DF es el valor inicial de las medidas de desarrollo financiero. GDPPLN es el logaritmo del PIB per capita en términos } \\
\text { PPP. INFLA es la tasa de inflación. XM es la suma de importaciones y exportaciones sobre el PIB. }\end{array}$} \\
\hline
\end{tabular}

Fuente: Elaboración propia con estimaciones de Econometric Views y datos del Banco Mundial: World Development Indicador 2003 y La Porta et al., 2006. 
Cuadro 5

Desarrollo del sistema financiero y autoridad de la ley

\begin{tabular}{|c|c|c|c|c|c|c|}
\hline & $\begin{array}{c}\text { Signo } \\
\text { esperado }\end{array}$ & $D C P S$ & $D C P B S$ & $L L Y$ & STTV & STTR \\
\hline RLAW & + & $\begin{array}{c}9.921261 \\
(9.168988)\end{array}$ & $\begin{array}{c}1.310299 \\
(8.511428)\end{array}$ & $\begin{array}{l}-5.414175 \\
(8.826559)\end{array}$ & $\begin{array}{l}-17.45545 \\
(14.48684)\end{array}$ & $\begin{array}{l}-34.9017 \\
(25.98695)\end{array}$ \\
\hline $\mathrm{DF}_{\mathrm{I}}$ & - & $\begin{array}{l}-0.116349 \\
(0.237173)\end{array}$ & $\begin{array}{l}-0.182252 \\
(0.311023)\end{array}$ & $\begin{array}{l}-0.015623 \\
(0.184093)\end{array}$ & $\begin{array}{l}-0.075906 \\
(0.86215)\end{array}$ & $\begin{array}{l}-0.468709^{*} \\
(0.298091)\end{array}$ \\
\hline GDPPLN & + & $\begin{array}{c}2.083079 \\
(12.09078)\end{array}$ & $\begin{array}{c}-1.356667 \\
(17.22178)\end{array}$ & $\begin{array}{r}8.297569 \\
(11.14482)\end{array}$ & $\begin{array}{l}32.38444 * * \\
(19.00783)\end{array}$ & $\begin{array}{c}25.23753 \\
(35.65519)\end{array}$ \\
\hline INFLA & - & $\begin{array}{l}-0.076785 \\
(0.096602)\end{array}$ & $\begin{array}{l}-0.062519 \\
(0.132457)\end{array}$ & $\begin{array}{l}-0.113733 \\
(0.114296)\end{array}$ & $\begin{array}{c}0.23988 \\
(0.489929)\end{array}$ & $\begin{array}{c}0.191891 \\
(1.507567)\end{array}$ \\
\hline $\mathrm{xM}$ & + & $\begin{array}{l}0.241493 * * * \\
(0.099223)\end{array}$ & $\begin{array}{c}0.184925^{*} \\
(0.136963)\end{array}$ & $\begin{array}{l}0.181795 * * * * \\
(0.064069)\end{array}$ & $\begin{array}{l}-0.004142 \\
(0.190399)\end{array}$ & $\begin{array}{l}-0.151155 \\
(0.300358)\end{array}$ \\
\hline D1 & & $\begin{array}{c}-0.224876 \\
(17.69569)\end{array}$ & $\begin{array}{r}0.101207 \\
(20.63716)\end{array}$ & $\begin{array}{c}-9.999381 \\
(14.84783)\end{array}$ & $\begin{array}{l}-23.72025 \\
(21.64856)\end{array}$ & $\begin{array}{l}-23.6397 \\
(41.79662)\end{array}$ \\
\hline D2 & & $\begin{array}{c}-5.239994 \\
(22.51607)\end{array}$ & $\begin{array}{c}29.73319 \\
(38.41087)\end{array}$ & $\begin{array}{l}-4.543855 \\
(24.29385)\end{array}$ & $\begin{array}{c}8.996646 \\
(33.59065)\end{array}$ & $\begin{array}{l}27.31295 \\
(54.0742)\end{array}$ \\
\hline r-cuadrado & & 0.29 & 0.24 & 0.24 & 0.24 & 0.16 \\
\hline Observaciones & & 46 & 46 & 37 & 42 & 35 \\
\hline
\end{tabular}

Estimación con мсо, entre paréntesis están los errores estándar consistentes con heterocedasticidad.

$*(* *)[* * *]$ y $\{* * * *\}$ indican significancia al nivel de $20 \%(10 \%)[5 \%]$ y $\{1 \%\}$.

Desarrollo institucional: autoridad de la ley (RLAW). Desarrollo financiero: crédito doméstico al sector privado (DCPS), crédito doméstico proporcionado por el sector bancario (DCPBS), pasivos líquidos o M3 (LLY), acciones comercializadas, valor total (STTV) y acciones comercializadas, proporción al volumen de ventas (STTR). DF, es el valor inicial de las medidas de desarrollo financiero. GDPPLN es el logaritmo del PIB per capita en términos PPP. INFLA es la tasa de inflación. XM es la suma de importaciones y exportaciones sobre el PIB. D1 país desarrollado, D2 país emergente.

Fuente: Elaboración propia con estimaciones de Econometric Views y datos del Banco Mundial: World Development Indicador 2003 y Kaufmann et al., (2003).

Cuadro 6

Desarrollo del sistema financiero y corrupción

\begin{tabular}{|c|c|c|c|c|c|c|}
\hline & $\begin{array}{c}\text { Signo } \\
\text { esperado }\end{array}$ & $D C P S$ & $D C P B S$ & $L L Y$ & STTV & $S T T R$ \\
\hline CORRU & + & $\begin{array}{l}-0.552151 \\
(8.243096)\end{array}$ & $\begin{array}{l}-13.46065 \\
(9.668977)\end{array}$ & $\begin{array}{c}-11.89705 * * \\
(6.861237)\end{array}$ & $\begin{array}{c}-5.633689 \\
(13.39397)\end{array}$ & $\begin{array}{l}-29.61932 \\
(21.738)\end{array}$ \\
\hline $\mathrm{DF}_{\mathrm{I}}$ & - & $\begin{array}{l}-0.084111 \\
(0.243407)\end{array}$ & $\begin{array}{l}-0.164714 \\
(0.286628)\end{array}$ & $\begin{array}{l}-0.029721 \\
(0.144376)\end{array}$ & $\begin{array}{l}-0.103498 \\
(0.891221)\end{array}$ & $\begin{array}{l}-0.592849 * * * \\
(0.277646)\end{array}$ \\
\hline GDPPLN & + & $\begin{array}{c}8.745722 \\
(9.552604)\end{array}$ & $\begin{array}{c}6.983642 \\
(13.91937)\end{array}$ & $\begin{array}{l}11.11777 \\
(9.450721)\end{array}$ & $\begin{array}{c}23.79966 \\
(19.62067)\end{array}$ & $\begin{array}{c}25.01205 \\
(36.45461)\end{array}$ \\
\hline INFLA & - & $\begin{array}{l}-0.123271 * \\
(0.095834)\end{array}$ & $\begin{array}{l}-0.153442 \\
(0.122721)\end{array}$ & $\begin{array}{l}-0.173426^{*} \\
(0.108377)\end{array}$ & $\begin{array}{c}0.266018 \\
(0.427116)\end{array}$ & $\begin{array}{c}0.138881 \\
(1.446408)\end{array}$ \\
\hline XM & + & $\begin{array}{l}0.256789 * * * \\
(0.104927)\end{array}$ & $\begin{array}{c}0.189307^{*} \\
(0.134536)\end{array}$ & $\begin{array}{l}0.176811 * * * * \\
(0.062282)\end{array}$ & $\begin{array}{l}-0.03325 \\
(0.179541)\end{array}$ & $\begin{array}{l}-0.170726 \\
(0.291744)\end{array}$ \\
\hline D1 & & $\begin{array}{l}-4.372711 \\
(17.0776)\end{array}$ & $\begin{array}{c}-2.076249 \\
(18.62855)\end{array}$ & $\begin{array}{c}-8.957726 \\
(14.05029)\end{array}$ & $\begin{array}{l}-16.58941 \\
(20.69942)\end{array}$ & $\begin{array}{l}-21.64134 \\
(38.71048)\end{array}$ \\
\hline D2 & & $\begin{array}{r}0.379041 \\
(25.72401)\end{array}$ & $\begin{array}{c}44.34527 \\
(41.44474)\end{array}$ & $\begin{array}{r}7.053167 \\
(24.45023)\end{array}$ & $\begin{array}{c}5.910062 \\
(34.10228)\end{array}$ & $\begin{array}{c}26.12529 \\
(51.04325)\end{array}$ \\
\hline r-cuadra & & 0.26 & 0.27 & 0.32 & 0.21 & 0.14 \\
\hline Observa & iones & 46 & 46 & 37 & 42 & 35 \\
\hline
\end{tabular}

Estimación con MCO, entre paréntesis están los errores estándar consistentes con heterocedasticidad.

$*(* *)[* * *]$ y $\{* * * *\}$ indican significancia al nivel de $20 \%(10 \%)[5 \%]$ y $\{1 \%\}$

Desarrollo institucional: control de la corrupción (CORRU). Desarrollo financiero: crédito doméstico al sector privado (DCPS), crédito doméstico proporcionado por el sector bancario (DCPBS), pasivos líquidos o M3 (LLY), acciones comercializadas, valor total (STTV) y acciones comercializadas, proporción al volumen de ventas (STTR). DF es el valor inicial de las medidas de desarrollo financiero. GDPPLN es el logaritmo del PIB per capita en términos PPP. INFLA es la tasa de inflación. XM es la suma de importaciones y exportaciones sobre el PIB. D1 país desarrollado, D2 país emergente.

Fuente: Elaboración propia con estimaciones de Econometric Views y datos del Banco Mundial: World Development Indicador 2003 y Kaufmann et al., (2003). 
Cuadro 7

Desarrollo del sistema financiero y riesgo de expropiación

\begin{tabular}{|c|c|c|c|c|c|c|}
\hline & $\begin{array}{l}\text { gno } \\
\text { erado }\end{array}$ & $D C P S$ & $D C P B S$ & $L L Y$ & STTV & STTR \\
\hline EXPROPIA & + & $\begin{array}{l}12.15646^{* * * *} \\
(5.330946)\end{array}$ & $\begin{array}{l}10.91088 * * * \\
(5.069993)\end{array}$ & $\begin{array}{l}8.549727 * * \\
(5.044065)\end{array}$ & $\begin{array}{r}9.938857 \\
(11.56957)\end{array}$ & $\begin{array}{l}11.3942 \\
(13.24917)\end{array}$ \\
\hline $\mathrm{DF}_{\mathrm{I}}$ & - & $\begin{array}{l}-0.127018 \\
(0.233398)\end{array}$ & $\begin{array}{l}-0.190331 \\
(0.301932)\end{array}$ & $\begin{array}{l}-0.059643 \\
(0.184822)\end{array}$ & $\begin{array}{l}-0.167836 \\
(0.917117)\end{array}$ & $\begin{array}{l}-0.551049^{*} \\
(0.346886)\end{array}$ \\
\hline GDPPLN & + & $\begin{array}{c}-1.578004 \\
(11.16563)\end{array}$ & $\begin{array}{c}-9.834388 \\
(16.73237)\end{array}$ & $\begin{array}{l}-0.339087 \\
(9.50243)\end{array}$ & $\begin{array}{c}12.41701 \\
(14.70183)\end{array}$ & $\begin{array}{c}-3.372928 \\
(27.50555)\end{array}$ \\
\hline INFLA & - & $\begin{array}{l}-0.110492 \\
(0.097675)\end{array}$ & $\begin{array}{l}-0.05596 \\
(0.132232)\end{array}$ & $\begin{array}{l}-0.08441 \\
(0.097372)\end{array}$ & $\begin{array}{c}0.327088 \\
(0.360987)\end{array}$ & $\begin{array}{c}0.331945 \\
(1.335212)\end{array}$ \\
\hline XM & + & $\begin{array}{l}0.234043 * * * \\
(0.097713)\end{array}$ & $\begin{array}{c}0.167711 \\
(0.133183)\end{array}$ & $\begin{array}{l}0.164376^{* * * *} \\
(0.066428)\end{array}$ & $\begin{array}{l}-0.05935 \\
(0.168749)\end{array}$ & $\begin{array}{l}-0.263339 \\
(0.274682)\end{array}$ \\
\hline D1 & & $\begin{array}{l}-2.227416 \\
(16.5988)\end{array}$ & $\begin{array}{r}1.437485 \\
(19.24392)\end{array}$ & $\begin{array}{c}-9.43216 \\
(14.1977)\end{array}$ & $\begin{array}{l}-14.52447 \\
(19.63207)\end{array}$ & $\begin{array}{l}-13.52313 \\
(35.80779)\end{array}$ \\
\hline D2 & & $\begin{array}{l}-12.20132 \\
(20.86752)\end{array}$ & $\begin{array}{c}19.45237 \\
(37.01447)\end{array}$ & $\begin{array}{l}-22.81626 \\
(25.25619)\end{array}$ & $\begin{array}{l}-10.10685 \\
(44.39793)\end{array}$ & $\begin{array}{l}-14.6402 \\
(68.20903)\end{array}$ \\
\hline r-cuadrado & & 0.32 & 0.26 & 0.27 & 0.22 & 0.10 \\
\hline observaciones & & 46 & 46 & 37 & 42 & 35 \\
\hline \multicolumn{7}{|c|}{$\begin{array}{l}\text { Desarrollo institucional: riesgo de expropiación (EXPROPIA). Desarrollo financiero: crédito doméstico al sector privado (DCPS), crédito doméstico } \\
\text { proporcionado por el sector bancario (DCPBS), pasivos líquidos o } 3 \text { (LLY), acciones comercializadas, valor total (STTV) y acciones comercializadas } \\
\text { proporción al volumen de ventas (STTR). DF } \text { es el valor inicial de las medidas de desarrollo financiero. GDPPLN es el logaritmo del PIB per capita }\end{array}$} \\
\hline
\end{tabular}

Fuente: Elaboración propia con estimaciones de Econometric Views y datos del Banco Mundial: World Development Indicador 2003 y Glaeser et al., (2004).

Cuadro 8

Desarrollo del sistema financiero y acceso a acciones

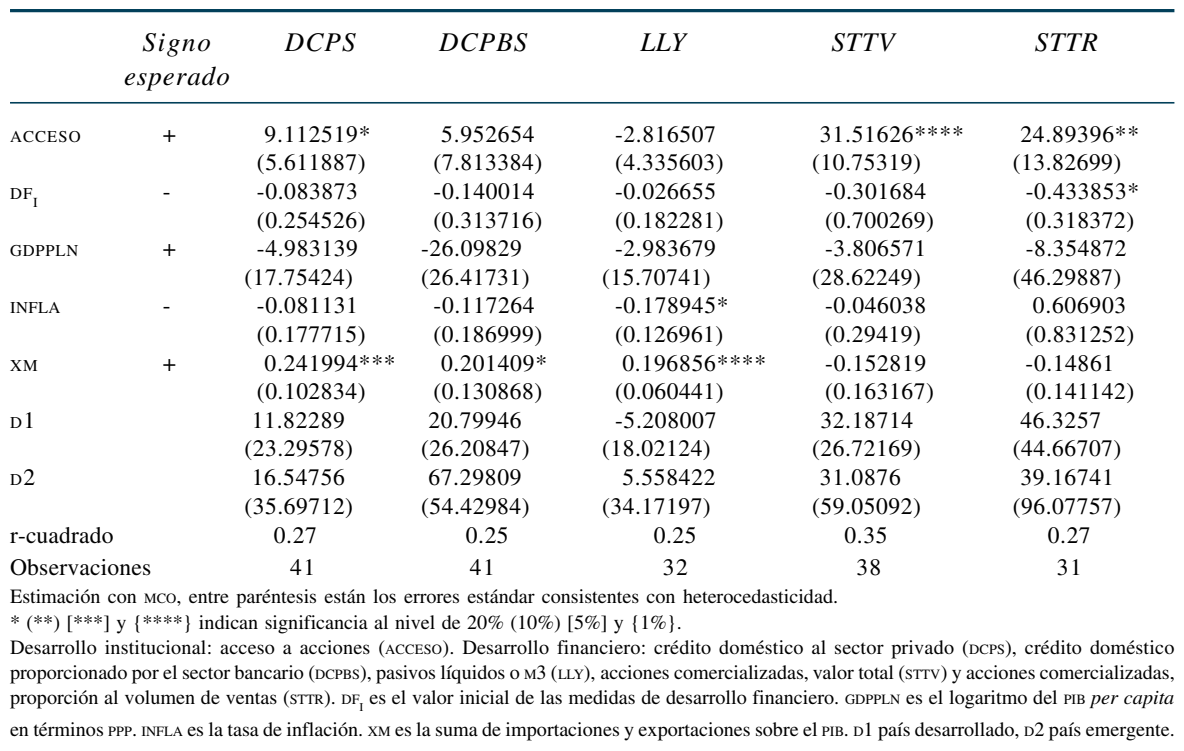

Fuente: Elaboración propia con estimaciones de Econometric Views y datos del Banco Mundial: World Development Indicador 2003 y La Porta et al., (2006). 
Cuadro 9

Desarrollo del sistema financiero y desconcentración de la propiedad

\begin{tabular}{|c|c|c|c|c|c|c|}
\hline & $\begin{array}{l}\text { gno } \\
\text { erado }\end{array}$ & $D C P S$ & $D C P B S$ & $L L Y$ & STTV & STTR \\
\hline DESCONPR & + & $\begin{array}{l}74.81458 * * * \\
(29.88789)\end{array}$ & $\begin{array}{l}72.44777 * * \\
(38.78269)\end{array}$ & $\begin{array}{c}37.21869 \\
(32.38686)\end{array}$ & $\begin{array}{l}175.0608 * * * \\
(83.32369)\end{array}$ & $\begin{array}{l}190.9802^{*} \\
(122.2623)\end{array}$ \\
\hline $\mathrm{DF}_{\mathrm{I}}$ & - & $\begin{array}{l}-0.164395 \\
(0.206416)\end{array}$ & $\begin{array}{l}-0.198816 \\
(0.270988)\end{array}$ & $\begin{array}{l}-0.052588 \\
(0.156558)\end{array}$ & $\begin{array}{l}-0.981165 \\
(0.850107)\end{array}$ & $\begin{array}{l}-0.504112 * * \\
(0.255609)\end{array}$ \\
\hline GDPPLN & + & $\begin{array}{r}4.930084 \\
(11.55872)\end{array}$ & $\begin{array}{l}-4.659446 \\
(19.23499)\end{array}$ & $\begin{array}{c}4.568058 \\
(11.07891)\end{array}$ & $\begin{array}{c}17.81026 \\
(15.55098)\end{array}$ & $\begin{array}{c}-8.778049 \\
(31.75481)\end{array}$ \\
\hline INFLA & - & $\begin{array}{l}-0.096342 \\
(0.100585)\end{array}$ & $\begin{array}{l}-0.036553 \\
(0.135218)\end{array}$ & $\begin{array}{l}-0.076058 \\
(0.106168)\end{array}$ & $\begin{array}{c}0.379902 \\
(0.431504)\end{array}$ & $\begin{array}{c}0.541035 \\
(1.295181)\end{array}$ \\
\hline $\mathrm{XM}$ & + & $\begin{array}{l}0.28332 * * * * \\
(0.095251)\end{array}$ & $\begin{array}{l}0.215144 * * \\
(0.129442)\end{array}$ & $\begin{array}{l}0.185841 * * * * \\
(0.062109)\end{array}$ & $\begin{array}{c}0.037541 \\
(0.157409)\end{array}$ & $\begin{array}{l}-0.130731 \\
(0.228638)\end{array}$ \\
\hline D1 & & $\begin{array}{c}2.3526 \\
(18.13546)\end{array}$ & $\begin{array}{l}6.07241 \\
(22.20126)\end{array}$ & $\begin{array}{l}-7.236525 \\
(15.28268)\end{array}$ & $\begin{array}{c}-8.275728 \\
(18.21288)\end{array}$ & $\begin{array}{c}5.680362 \\
(36.01616)\end{array}$ \\
\hline D2 & & $\begin{array}{r}2.038447 \\
(25.22987)\end{array}$ & $\begin{array}{l}32.25956 \\
(39.36497)\end{array}$ & $\begin{array}{l}-13.63726 \\
(24.13485)\end{array}$ & $\begin{array}{c}-1.218846 \\
(38.78249)\end{array}$ & $\begin{array}{l}12.11364 \\
(62.0592)\end{array}$ \\
\hline r-cuadrado & & 0.35 & 0.29 & 0.26 & 0.32 & 0.21 \\
\hline Observacione & & 46 & 46 & 37 & 42 & 35 \\
\hline \multicolumn{7}{|c|}{$\begin{array}{l}\text { Desarrollo institucional: desconcentración de la propiedad (DESCONPR). Desarrollo financiero: crédito doméstico al sector privado (DCPS), crédito } \\
\text { doméstico proporcionado por el sector bancario (DCPBS), pasivos líquidos o M3 (LLY), acciones comercializadas, valor total (STTV) y acciones } \\
\text { comercializadas, proporción al volumen de ventas (STTR). DF, es el valor inicial de las medidas de desarrollo financiero. GDPPLN es el logaritmo } \\
\text { del PIB per capita en términos PPP. INFLA es la tasa de inflación. XM es la suma de importaciones y exportaciones sobre el PIB. D1 país desarrollado, } \\
\text { D2 país emergente. }\end{array}$} \\
\hline
\end{tabular}

Fuente: Elaboración propia con estimaciones de Econometric Views y datos del Banco Mundial: World Development Indicador 2003 y La Porta et al., (2006).

Cuadro 10

Desarrollo del sistema financiero y desconcentración bancaria

\begin{tabular}{|c|c|c|c|c|c|c|}
\hline & $\begin{array}{c}\text { Signo } \\
\text { esperado }\end{array}$ & $D C P S$ & $D C P B S$ & $L L Y$ & STTV & STTR \\
\hline DESCONB & + & $\begin{array}{c}42.7923^{*} \\
(31.08632)\end{array}$ & $\begin{array}{c}64.22929^{*} \\
(45.06417)\end{array}$ & $\begin{array}{l}49.8465 * * * * \\
(18.34838)\end{array}$ & $\begin{array}{c}-3.041581 \\
(57.31079)\end{array}$ & $\begin{array}{c}-34.31333 \\
(111.4105)\end{array}$ \\
\hline $\mathrm{DF}_{\mathrm{I}}$ & - & $\begin{array}{l}-0.058551 \\
(0.206932)\end{array}$ & $\begin{array}{l}-0.157913 \\
(0.26316)\end{array}$ & $\begin{array}{l}-0.018904 \\
(0.119636)\end{array}$ & $\begin{array}{l}-0.045881 \\
(0.916115)\end{array}$ & $\begin{array}{l}-0.466345 \\
(0.377587)\end{array}$ \\
\hline GDPPLN & + & $\begin{array}{l}12.41046 \\
(9.861551)\end{array}$ & $\begin{array}{c}5.41968 \\
(15.54693)\end{array}$ & $\begin{array}{c}10.20175 \\
(10.27118)\end{array}$ & $\begin{array}{c}19.50382 \\
(20.61492)\end{array}$ & $\begin{array}{c}-1.092335 \\
(36.75259)\end{array}$ \\
\hline INFLA & - & $\begin{array}{l}-0.192026^{* *} \\
(0.112241)\end{array}$ & $\begin{array}{l}-0.175762 * \\
(0.12483)\end{array}$ & $\begin{array}{l}-0.181756^{*} \\
(0.120289)\end{array}$ & $\begin{array}{c}0.304612 \\
(0.404519)\end{array}$ & $\begin{array}{c}0.280525 \\
(1.329123)\end{array}$ \\
\hline хм & + & $\begin{array}{l}0.29939 * * * * \\
(0.094137)\end{array}$ & $\begin{array}{l}0.2502 * * * \\
(0.11753)\end{array}$ & $\begin{array}{l}0.202271 * * * * \\
(0.059532)\end{array}$ & $\begin{array}{l}-0.041606 \\
(0.156617)\end{array}$ & $\begin{array}{l}-0.300004 \\
(0.405117)\end{array}$ \\
\hline D 1 & & $\begin{array}{l}-16.43011 \\
(18.71945)\end{array}$ & $\begin{array}{l}-18.25107 \\
(21.01842)\end{array}$ & $\begin{array}{l}-22.71051 \\
(15.06371)\end{array}$ & $\begin{array}{l}-14.02385 \\
(32.79209)\end{array}$ & $\begin{array}{c}0.809863 \\
(46.44357)\end{array}$ \\
\hline D2 & & $\begin{array}{l}-10.99341 \\
(23.10145)\end{array}$ & $\begin{array}{c}14.99457 \\
(35.91965)\end{array}$ & $\begin{array}{l}-21.63316 \\
(22.76918)\end{array}$ & $\begin{array}{r}1.782541 \\
(47.59677)\end{array}$ & $\begin{array}{c}12.98314 \\
(76.03371)\end{array}$ \\
\hline r-cuadrado & & 0.31 & 0.30 & 0.37 & 0.21 & 0.10 \\
\hline Observaciones & & 46 & 46 & 37 & 42 & 35 \\
\hline
\end{tabular}

Fuente: Elaboración propia con estimaciones de Econometric Views y datos del Banco Mundial: World Development Indicador 2003 y Beck et al., (1999). 
Muestra y clasificación de países

\begin{tabular}{|c|c|c|}
\hline Desarrollados (21) & Emergentes (15) & Subdesarrollados (11) \\
\hline Alemania (GELO) & Argentina (FRLO) & Ecuador (FRLO) \\
\hline Australia (UKLO) & Brasil (FRLO) & Egipto (FRLO) \\
\hline Austria (GELO) & Colombia (FRLO) & Filipinas (FRLO) \\
\hline Bélgica (FRLO) & Corea (GELO) & India (UKLO) \\
\hline Canadá (UKLO) & Chile (FRLO) & Indonesia (FRLO) \\
\hline Dinamarca (sCLO) & Israel (UKLO) & Jordania (FRLO) \\
\hline España (FRLO) & Malasia (UKLO) & Kenia (UKLO) \\
\hline Estados Unidos (UKLO) & México (FRLO) & Nigeria (UKLO) \\
\hline Finlandia (SCLO) & Perú (FRLO) & Pakistán (UKLO) \\
\hline Francia (FRLO) & Singapur (UKLO) & Sri Lanka (UKLO) \\
\hline Grecia (FRLO) & Sudáfrica (UKLO) & Zimbabwe (UKLO) \\
\hline Holanda (FRLO) & Tailandia (UKLO) & \\
\hline Irlanda (UKLO) & Turquía (FRLO) & \\
\hline Italia (FRLO) & Uruguay (FRLO) & \\
\hline Japón (GELO) & Venezuela (FRLO) & \\
\hline \multicolumn{3}{|l|}{ Noruega (sCLO) } \\
\hline \multicolumn{3}{|l|}{ Nueva Zelanda (UKLO) } \\
\hline \multicolumn{3}{|l|}{ Portugal (FRLO) } \\
\hline \multicolumn{3}{|l|}{ Reino Unido (UKLO) } \\
\hline \multicolumn{3}{|l|}{ Suecia (SCLO) } \\
\hline \multicolumn{3}{|l|}{ Suiza (GELO) } \\
\hline \multicolumn{3}{|c|}{$\begin{array}{l}\text { De } 208 \text { países para los que se tiene información del PIB en términos PPP en } 2000 \text {, se ha calculado la } \\
\text { media y la desviación estándar. Los países que se encuentran en media desviación estándar por arriba } \\
\text { y por debajo de la media son clasificados como emergentes. Arriba y debajo de dicho grupo se } \\
\text { encuentran los desarrollados y los subdesarrollados. Singapur, Israel y Corea tienen un PIB en PPP lo } \\
\text { suficientemente alto como para entrar en la clasificación de desarrollados. Sin embargo, son considerados } \\
\text { países emergentes porque la literatura económica los trata como tal. }\end{array}$} \\
\hline
\end{tabular}

Fuente: World Development Indicator 2003.

UKLO: Origen de la legislación comercial británico. FRLO: Origen de la legislación comercial francés.

SCLO: Origen de la legislación comercial escandinavo. GELO: Origen de la legislación comercial alemán. 

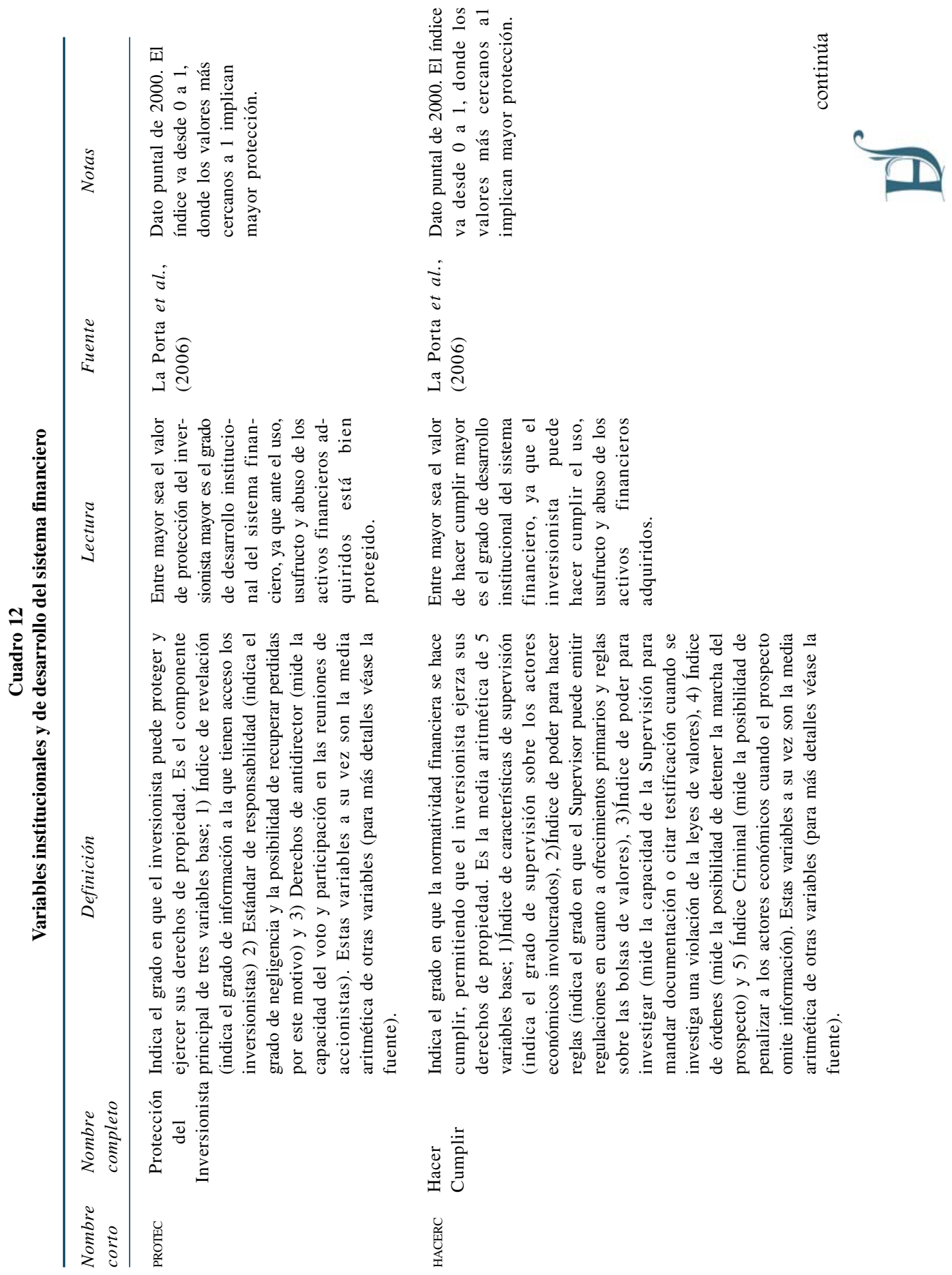

$\ddot{8}$

$\check{2}$

ํํㅇ

తึ

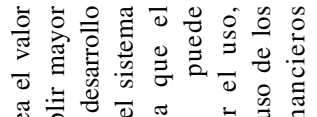

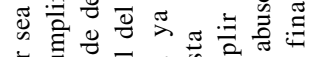

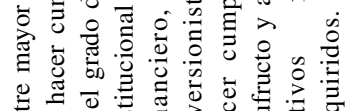

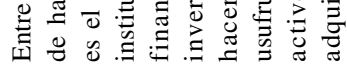

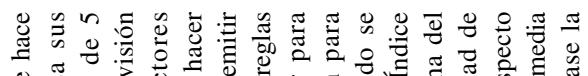

\&

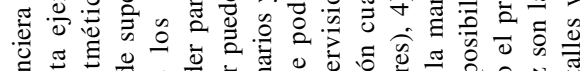

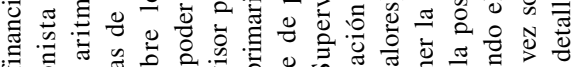

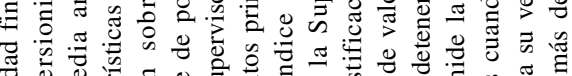

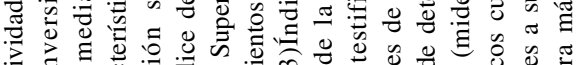

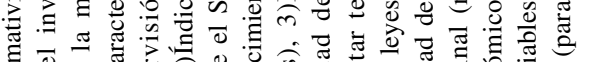

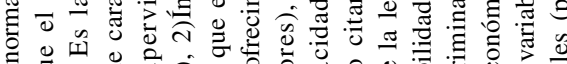

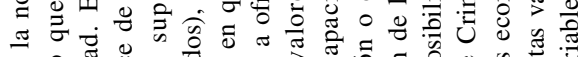

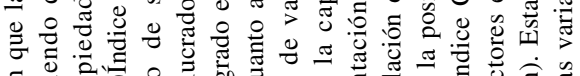

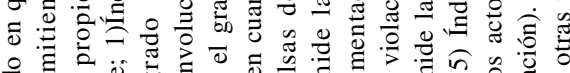

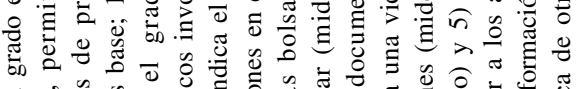

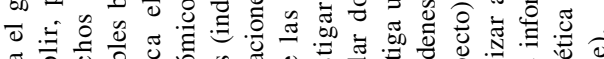

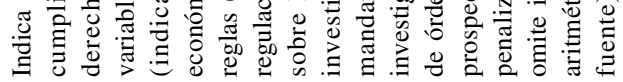

竞:

曽 


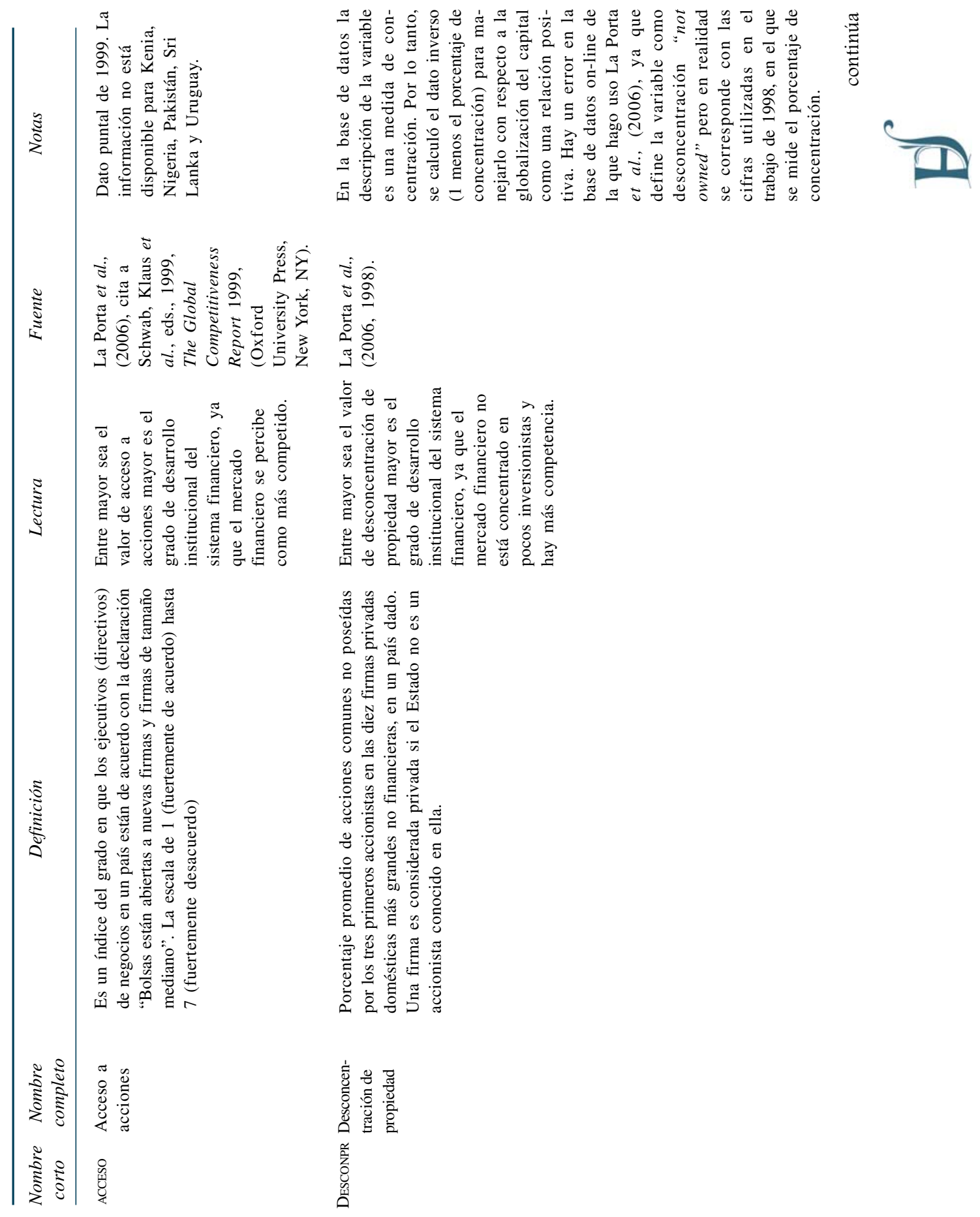




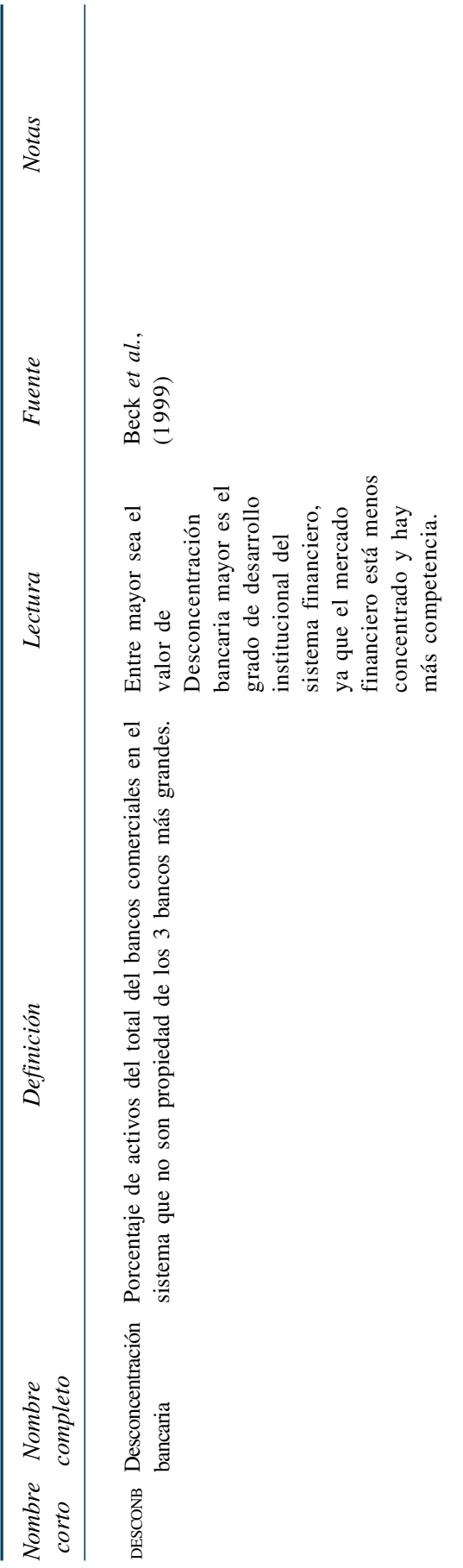

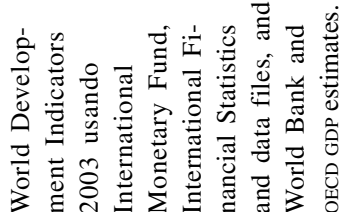

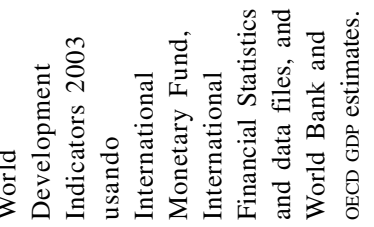

迹

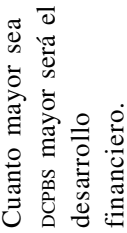

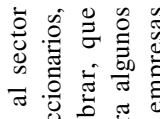

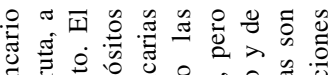

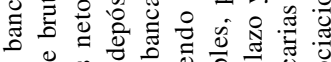

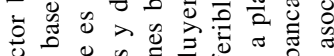

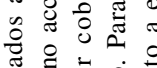

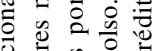

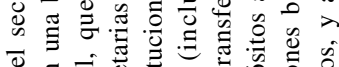

奈焉

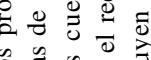

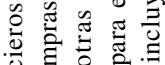

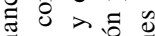

: की 0

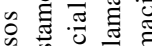

范苾

๖

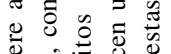

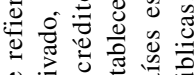

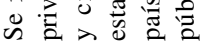

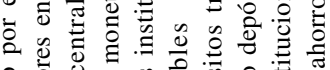

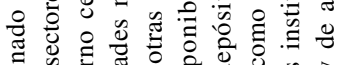

응

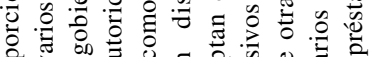

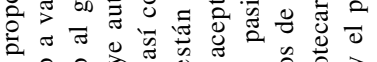

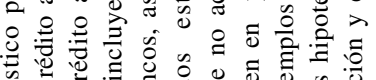

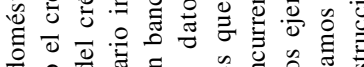

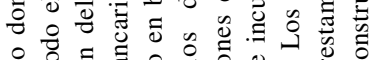

응 응

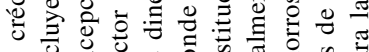

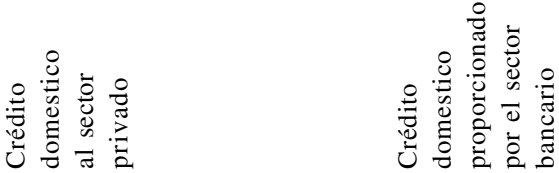

气્ڤ

菴 

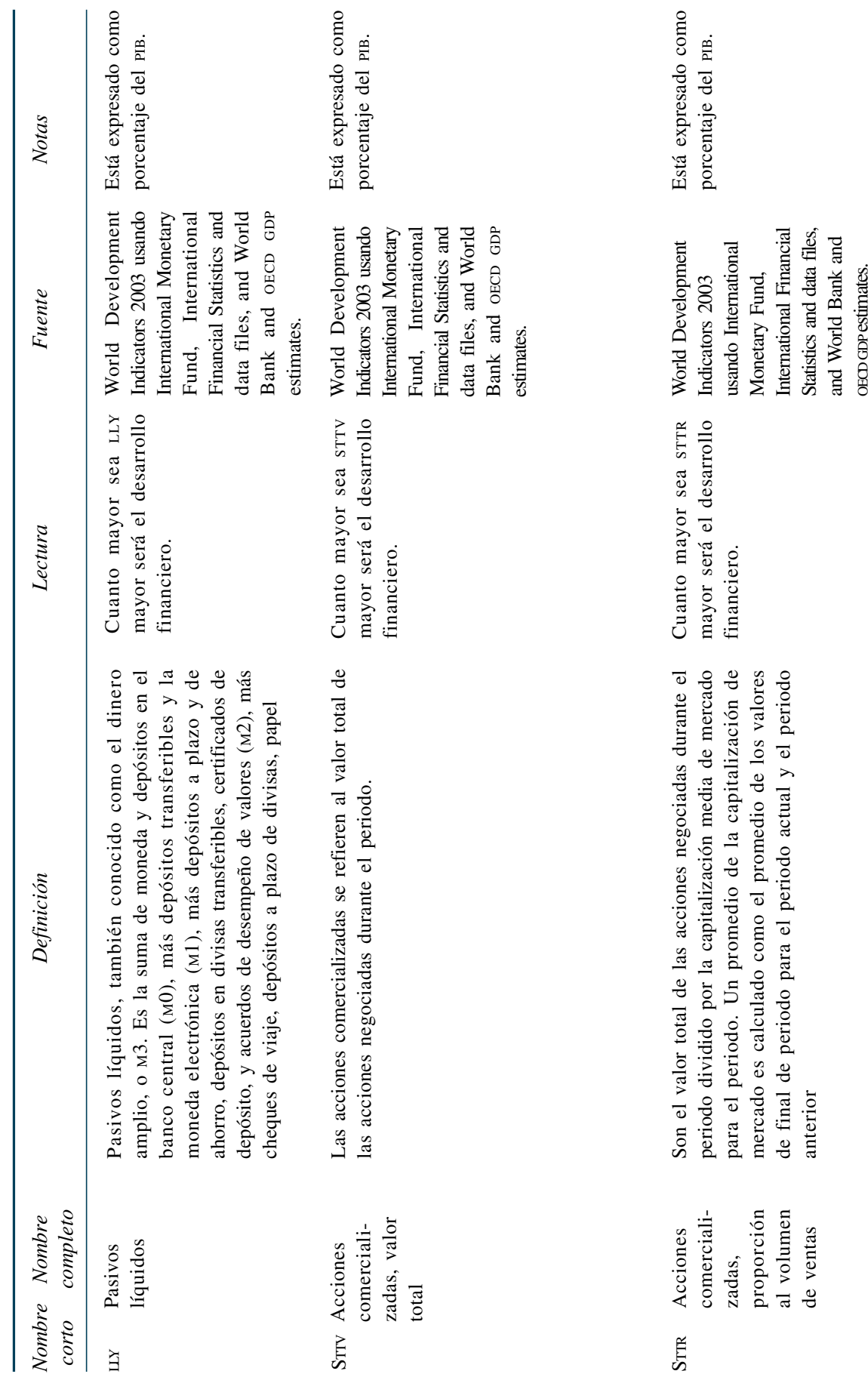